\title{
GEOLOGIA E GEOCRONOLOGIA Pb-Pb DE ROCHAS GRANITICAS E VULCÂNICAS ÁCIDAS A INTERMEDIÁRIAS PALEOPROTEROZÓICAS DA PROVÍNCIA PITINGA, CRATON AMAZÔNICO
}

\author{
JOSÉ MAXIMINO TADEU MIRAS FERRON ${ }^{1-2}$; ARTUR CEZAR BASTOS NETO'; EVANDRO \\ FERNANDES DE LIMA ${ }^{1}$; HILTON TULIO COSTI ${ }^{3}$; CANDIDO AUGUSTO VELOSO MOURA ${ }^{4}$; \\ MAURÍCIO PRADO ${ }^{1-2}$; RONALDO PIEROSAN ${ }^{1}$ \& MARCO ANTONIO GALARZA ${ }^{4}$
}

\begin{abstract}
Resumo A Província Pitinga é responsável por $60 \%$ da produção brasileira de estanho e cerca de $3 \%$ da produção mundial desse metal não ferroso. Associados ao Sn ocorrem reservas consideráveis de Nb, Ta e F (criolita), além de teores anômalos de $\mathrm{Zr}$, Y, Rb, U, Th e ETRP. O contexto geológico da Província Pitinga é constituído predominantemente por rochas de idade Paleoproterozóica, representadas por unidades vulcânicas e graníticas enquadradas no Supergrupo Uatumã, por granitóides mais jovens, relacionados à Suite Madeira, e por uma unidade vulcano-sedimentar denominada Formação Urupi. As unidades graníticas das Suítes Mapuera e Madeira são representadas por oito plutons graníticos intrusivos em rochas vulcânicas ácidas e intermediárias do Grupo Iricoumé. Das unidades graníticas apenas as da Suite Madeira possuem informações geocronológicas prévias. Neste trabalho são apresentadas idades ${ }^{207} \mathrm{~Pb}{ }^{206} \mathrm{~Pb}$ em zircão de quatro unidades graníticas da Suíte Mapuera e de rochas vulcânicas encaixantes. Informações de campo, petrográficas e geoquímicas permitem distinguir na região dois pulsos magmáticos. O primeiro responsável pela geração de rochas vulcânicas e graníticas de idades entre 1.890 e $1.876 \mathrm{Ma}$. O segundo pulso magmático gerou rochas graníticas tipo-A entre 1.829 e $1.798 \mathrm{Ma}$. As rochas vulcânicas do Grupo Iricoumé foram divididas, com base em dados de campo e de sensores remotos, em três formações distintas, para as quais se propõe as denominações: Formação Divisor, Formação Paraíso e Formação Ouro Preto. As idades dessas unidades situam-se entre 1,89 e 1,88 Ga. Os dados de campo indicam que a Formação Urupi mostra intercalações de rochas piroclásticas. Estas rochas piroclásticas são interpretadas como pertencentes à Formação Paraiso, o que posiciona a Formação Urupi no Paleoproterozóico, corroborando sua correlação temporal com o Supergrupo Roraima. Todas essas unidades litológicas estão associadas a uma mega-estrutura distensional de forma arqueada e de dimensão regional, que abrange a totalidade da Província Pitinga. Os plutons graníticos da Suíte Mapuera ocupam as porções marginais da estrutura, que é preenchida por vulcânicas efusivas e piroclásticas do Grupo Iricoumé e sedimentos da Formação Urupi. O contexto tectônico sugere que a colocação das rochas efusivas e piroclásticas do Grupo Iricoumé, na Província Pitinga, foi controlada por processos distensionais de subsidência de caldeiras no interior da mega-estrutura regional. A reativação desse sistema distensional, em período pós-Uatumã, permitiu o posicionamento dos plutons da suíte Madeira na parte central dessa mega-estrutura.
\end{abstract}

Palavras-chave: Província Pitinga, geocronologia, Suíte Mapuera, Grupo Iricoumé, Supergrupo Uatumã, Paleoproterozóico.

\begin{abstract}
GEOLOGY AND Pb-Pb GEOCHRONOLOGY OF PALEOPROTEROZOIC ACID TO INTERMEDIATE GRANITIC AND VOLCANIC ROCKS OF THE PITINGA PROVINCE, AMAZON CRATON The Pitinga Province is responsible for $60 \%$ of the Brazilian tin production, and about $3 \%$ of the world production of this not ferrous metal. Associates to the Sn occurs important reserves of $\mathrm{Nb}$, Ta and $\mathrm{F}$ (cryolite), beyond anomalous grades of $\mathrm{Zr}, \mathrm{Y}, \mathrm{Rb}, \mathrm{U}$, Th and HREE. The geological setting of the Pitinga Province consists in Paleoproterozoic, volcanic and granitic units of Uatumã Supergroup, younger granites related to the Madeira Suite and by the vulcano-sedimentary Urupi Formation. The granitic units of the Mapuera and Madeira Suite are represented by eight plutons that are intrusive in to acid and intermediate volcanic rocks of the Iricoumé Group. Only the granites of the Madeira Suite have previous geochronologic information.

This paper shows ${ }^{207} \mathrm{~Pb} /{ }^{206} \mathrm{~Pb}$ zircon ages of four granitic units of the Mapuera Suite and ${ }^{207} \mathrm{~Pb} /{ }^{206} \mathrm{~Pb}$ zircon ages of the volcanic rocks that enclose these plutons. Petrographic, geochemical and field data, allow us to distinguish two magmatic pulses in the region. The first one is responsible for the generation of volcanic and granitic rocks of ages between 1,890 and 1,876 My. The second magmatic pulse generated A type granites with ages ranging from 1,829 and 1,798 My. Based on field and remote sensor data, the volcanic rocks of the Iricoumé Group were divided in three formations, for which are proposed the names Divisor Formation, Paraíso Formation and Ouro Preto Formation. The ages of these units are around 1,89 and 1,88 Ga. The field data indicates that the Urupi Formation shows intercalations of pyroclastic rocks. These pyroclastic rocks are interpreted as part of the Paraíso Formation; consequently it locates the Urupi Formation in the Paleoproterozoic, suggesting its correlation with Roraima Supergrup. All these lithologic units are associated with a regional, extensional, arc-shaped structure, which encloses the whole Pitinga Province. Granitic plutons of the Mapuera Suite occupy the peripheral parts of the structure, which is filled by effusive and pyroclastic rocks of the Iricoumé Group, and sedimentary rocks of the Urupi Formation. The tectonic setting suggests that the emplacement of volcanic and pyroclastic rocks of the Iricoumé Group, in the Pitinga Province, was controlled by extensional processes of caldera collapse. Subsequent reactivation of the extensional system allowed the emplacement of the Madeira Suite, in the central portion of this wide structure.
\end{abstract}

Keywords: Pitinga Province, geochronology, Mapuera Suite, Iricoumé Group, Uatumã Supergroup, Paleoproterozoic.

INTRODUÇÃO A Província Pitinga situa-se no Estado do Amazonas, a $325 \mathrm{~km}$ ao norte de Manaus, com coordenadas centrais de $0^{\circ} 45^{\prime} \mathrm{S}$ e $60^{\circ} 00^{\prime} \mathrm{W}$, abrangendo parte dos municípios de Presidente Figueiredo e Urucará (Figura 1).

As primeiras notícias sobre a ocorrência de cassiterita na região remontam a década de 70 , e são resultados de trabalhos de

\footnotetext{
1 - Universidade Federal do Rio Grande do Sul - UFRGS

2 - Mineração Taboca S.A.

3-Museu Paraense Emilio Goeldi - Belém-PA

4 - Universidade Federal do Pará - UFPA
} 


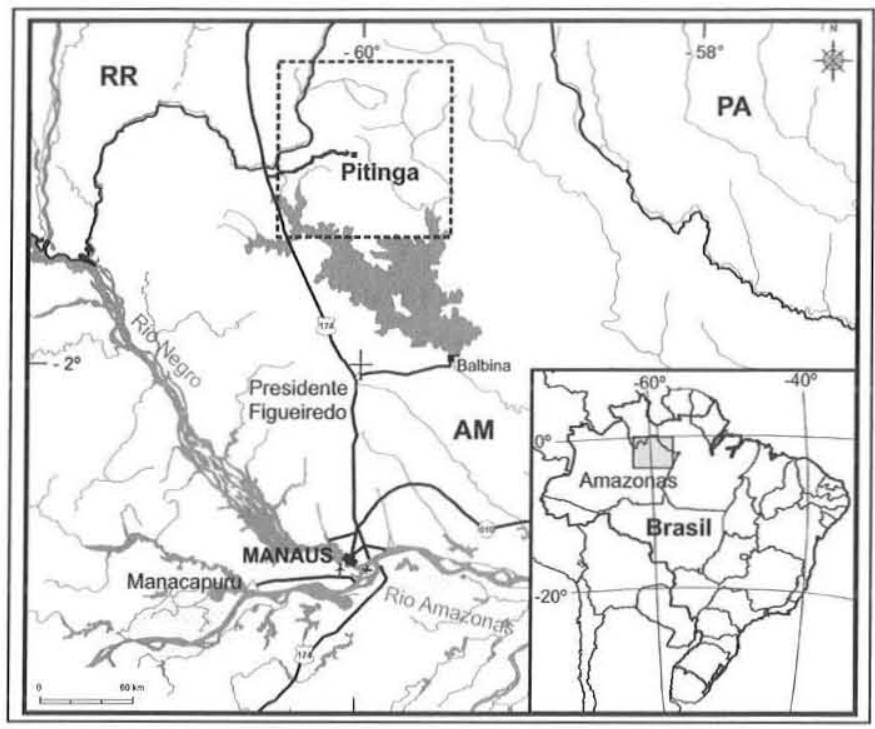

Figura I - Mapa de localização da Provincia Pitinga

mapeamento geológico desenvolvidos pela CPRM (Veiga Jr. et al., 1979). A Província apresenta importantes reservas, de classe mundial, de $\mathrm{Sn}, \mathrm{Nb}$, Ta e F (criolita) além de teores anômalos de $\mathrm{Zr}, \mathrm{Y}, \mathrm{Rb}, \mathrm{Th}, \mathrm{U}$ e ETR associados à rochas graníticas anorogênicas Paleoproterozóicas. Desde o início da lavra, na década de 80 , foram produzidos cerca de $343.000 \mathrm{t} \mathrm{Sn}$. Atualmente, além do Sn, também são explotados comercialmente $\mathrm{Nb}$ e Ta.

O contexto geológico da Província Pitinga é definido por um conjunto de rochas vulcânicas ácidas, intermediárias e rochas piroclásticas, atribuídas ao Grupo Iricoumé, e rochas graníticas consideradas como contemporâneas a essas rochas vulcânicas, agrupadas sob a denominação de Suíte Mapuera. Essas duas unidades integram o Supergrupo Uatumã e são relacionadas ao evento vulcano-plutônico Uatumã. As demais unidades são representadas por rochas graníticas estaníferas, mais jovens do que as rochas do Supergrupo Uatumã, denominadas Suíte Madeira, rochas sedimentares da Formação Urupi, rochas básicas toleiticas da Formação Quarenta Ilhas e básicas alcalinas da Formação Seringa. As idades de todas essas unidades variam entre 1,88 Ga (Supergrupo Uatumã) e 1,08 Ga (Formação Seringa).

O objetivo deste trabalho é apresentar os resultados iniciais do mapeamento geológico em escala 1:100.000 realizado nas unidades encaixantes dos granitos estaníferos da Província Pitinga, onde foram obtidos novos dados geológicos e geocronológicos relativos às rochas do Grupo Iricoumé e dados inéditos quanto à geocronologia da Suíte Mapuera nesta Província. Um dos resultados do mapeamento geológico realizado é a subdivisão do Grupo Iricoumé, na região, em três formações, cujas idades ${ }^{207} \mathrm{~Pb} / 206 \mathrm{~Pb}$ por evaporação em zircão situam-se em torno de $1,88 \mathrm{Ga}$. As informações aqui apresentadas visam posicionar a região do Pitinga no contexto geológico evolutivo regional e contribuir para o entendimento da evolução geológica deste setor do Craton Amazônico.

\section{GEOLOGIA DA PROVÍNCIA PITINGA}

Geologia regional A região de Pitinga insere-se tectonicamente na porção sul do Escudo das Guianas, parte integrante do Craton Amazônico (Almeida et al., 1981) e situa-se, segundo o modelo de províncias tectono-geocronológicas de Santos et al. (2000), no limite entre as Províncias Parima-Tapajós (2,10-1,87 Ga) e Amazônia Central, a leste (1,88-1,70 Ga), (Figura 2). Porém, o contexto tectônico em que se deu a formação das rochas mais antigas da região ainda é pouco conhecido em vista da bai- xa densidade de trabalhos de mapeamento em escala regional desenvolvidos nesse setor do craton. Um quadro resumido sobre as idades disponíveis para as unidades estratigráficas da região é mostrado na Tabela 1.

Nos trabalhos mais recentes (Faria et al., 2000), o Complexo Anauá é a unidade estratigráfica mais antiga, sendo composto por metatonalitos, metadioritos e metagranitos, além de granitóides isótropos, gnaisses, granulitos e milonitos derivados de rochas graníticas, com idade U-Pb em zircão de $2.028 \pm 9 \mathrm{Ma}$ (Faria et al., 2002). Esta unidade ainda não foi delimitada na região em torno da Província Pitinga, onde as seqüências do embasamento ainda estão indivisas, agrupadas sob a denominação de Complexo Guianense (Issler et al., 1974).

A unidade seguinte compreende uma série de granitóides cálcico-alcalinos, metaluminosos a peraluminosos. Nos trabaIhos pioneiros estas rochas eram agrupadas sob a denominação de Granodiorito Água Branca (Araújo Neto \& Moreira, 1976), ou Adamelito Água Branca (Veiga Jr. et al., 1979), com idades Rb-Sr entre 1951 (Santos \& Reis Neto, 1982) e $1910 \pm 47 \mathrm{Ma}$ (Jorge João et al., 1985). Este conjunto de rochas foi redefinido posteriormente como Suíte Intrusiva Água Branca (Oliveira et al., 1996), com idades ${ }^{207} \mathrm{~Pb} /{ }^{206} \mathrm{~Pb}$ por evaporação em monocristal de zircão entre $1960 \pm 21$ e $1938 \pm 37$ Ma (Almeida et al., 1997). Almeida et al. (2002, 2003), com base em dados obtidos em novos trabalhos de mapeamento e geocronologia, distinguiram dois domínios graníticos na região sul do estado de Roraima, previamente estudada por Faria et al. (1999), denominandoos Terreno Martins Pereira-Anauá, a norte, e Terreno Igarapé Azul-Água Branca, a sul. O Terreno Igarapé Azul-Água Branca situa-se próximo ao limite oeste/noroeste da Província Pitinga e é formado por granitos cálcico-alcalinos com idades entre 1,88 e 1,90 Ga (Almeida et al., 2002), que formam duas unidades litológicas distintas, nomeadas de Granito Igarapé Azul e Suíte Intrusiva Água Branca. O Granito Igarapé Azul compreende (muscovita)-biotita-granitos e raros granodioritos. A Suíte Intrusiva Água Branca é composta por uma fácies com hornblenda (dioritos, tonalitos, granodioritos, monzogranitos) e outra com biotita (granodioritos e monzogranitos).

Quimicamente, os granitóides da Suíte Água Branca são metaluminosos de natureza cálcico-alcalina. Apresentam teores relativamente baixos de $\mathrm{SiO}_{2}$, altos de $\mathrm{Ba}$ e baixas razões $\mathrm{Sr} / \mathrm{Ba}$ e Rb/Sr. Seus padrões de ETR apresentam discreta anomalia negativa de Eu e enriquecimento em ETR leves.

Seguindo os granitóides cálcico-alcalinos da Suíte Água Branca ocorrem rochas do Supergrupo Uatumã, que na região é representado pelo Grupo Iricoumé, constituido por rochas vulcânicas ácidas, intermediárias e piroclásticas associadas, e por granitóides da Suíte Mapuera.

Geologia da Província Pitinga A geologia da Província Pitinga é representada principalmente por rochas vulcânicas, extrusivas e piroclásticas do Grupo Iricoumé, granitos intrusivos agrupados na Suíte Mapuera, rochas sedimentares clásticas com intercalações de rochas piroclásticas, denominada Formação Urupi e granitos alcalinos tipo A, em geral portadores de mineralização de $\mathrm{Sn}$ e $\mathrm{Nb}$, agrupados na Suíte Madeira. O contexto geológico da Província Pitinga é completado por rochas intrusivas básicas toleiticas da Formação Quarenta Ilhas e intrusões e derrames básicos alcalinos da Formação Seringa, todas elas proterozóicas (Figura 3), encerrando-se com o desenvolvimento de extensas coberturas bauxítico-lateríticas terciárias e depósitos aluvionares quaternários. A Tabela 2 mostra o quadro atual do conhecimento a cerca das idades das rochas vulcânicas encaixantes dos granitos da Suíte Madeira, bem como os dados geocronológicos dessa própria suíte, e de uma idade determinada para as básicas toleiticas. 


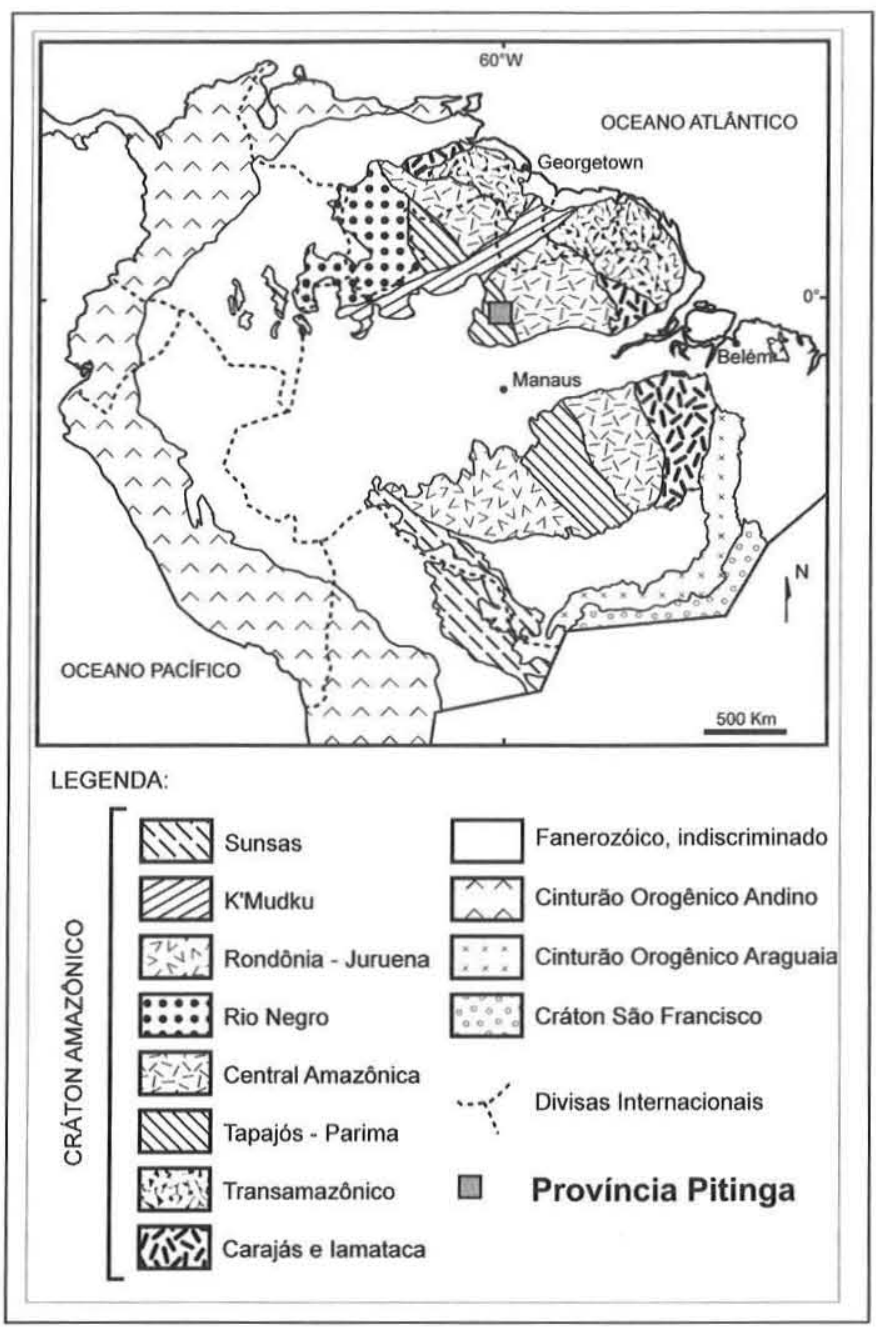

Figura 2 - Localização da Província Mineral de Pitinga no mapa de províncias geocronológicas do Craton Amazônico de Santos et al., (2000)

O mapeamento em escala 1:100.000 realizado como parte deste trabalho permitiu detalhar a geologia do Grupo Iricoumé na área da Província Pitinga, levando ao reconhecimento e delimitação de três unidades litológicas distintas dentro dessa unidade maior, cujas características serão descritas a seguir. Foram detalhados os contatos e a faciologia petrográfica de plutons graníticos que integram a Suíte Mapuera, denominados localmente de Simão, Rastro, Bom Futuro, Alto Pitinga e Pedreira, apresentando-se aqui os resultados de idades ${ }^{207} \mathrm{~Pb} /{ }^{206} \mathrm{~Pb}$ por evaporação em zircão dos quatro primeiros plutons. Foi também mapeada a área de ocorrência das rochas sedimentares clásticas da Formação Urupi, que mostram, em vários locais, intercalações de rochas piroclásticas ácidas.

GRUPO IRICOUMÉ As rochas vulcânicas do Grupo Iricoumé constituem a unidade de maior distribuição superficial da Província Pitinga, compreendendo rochas efusivas e hipabissais ácidas e intermediárias, e piroclásticas (tufos, ignimbritos e, subordinadamente, brechas vulcânicas e depósitos do tipo surge) de composição predominante ácida. Estudos geocronológicos prévios (Tabela 2) indicam idade de $1.888 \pm 3$ Ma para uma amostra de riolito, encaixante do Granito Madeira (Costi et al., 2000). As determinações geocronológicas realizadas ao longo do presente estudo (ver ítem 3) indicam que, na Província Pitinga, a totalidade destas rochas foram formadas neste período (Tabela 2).
Em função de características petrográficas e geoquímicas distintas e da possibilidade de sua separação cartográfica na escala do mapeamento realizado, as rochas do Grupo Iricoumé foram subdivididas em três unidades distintas, propondo-se neste trabalho as denominações: Formação Divisor, Formação Paraíso e Formação Ouro Preto.

Formação Divisor: é composta por rochas vulcânicas efusivas de composição intermediária, compreendendo andesitos, latitos e traquitos. Estas rochas distribuem-se em um arco, aproximadamente paralelo à borda norte de uma mega-estrutura de dimensão regional descrita por Ferron et al. (2002) nesta região (Figura 3). As determinações geocronológicas dessa unidade estão em andamento, contudo, devido às suas relações de campo com as demais unidades, acredita-se que sua idade deverá situar-se próxima à idade das formações Paraíso e Ouro Preto.

Formação Paraíso: compreende as rochas piroclásticas ácidas, representadas por ignimbritos, tufos cineríticos, tufos de cristais, e seus produtos de re-deposição, tais como arenitos tufáceos e brechas. Esta unidade ocorre em uma faixa de direção aproximadamente leste-oeste, ao norte do Granito Água Boa, circundando o Granito Europa e estendendo-se para sudeste até as proximidades do Granito Madeira. Ocorre também na região centro-leste da Província Pitinga, desde a borda sudeste do Granito Água Boa até as proximidades do rio Pitinga, onde interdigita-se com a Formação Urupi (Figura 3). Para esta unidade foi datada uma amostra de ignimbrito, que apresentou idade de ${ }^{207} \mathrm{~Pb} /{ }^{206} \mathrm{~Pb}$ em zircão de $1.882 \mathrm{Ma}$ (Tabela 2).

Formação Ouro Preto: é composta por rochas vulcânicas efusivas e hipabissais ácidas, tais como riolitos e dacitos. Sua principal área de exposição situa-se a norte do Granito Simão, envolvendo completamente o Granito Rastro, nos setores sul e sudoeste do Granito Madeira e a nordeste do Granito Água Boa e norte do Granito Bom Futuro (Figura 2). Foram datadas cinco amostras dessa unidade, cujos resultados apontam idades ${ }^{207} \mathrm{~Pb} /$ ${ }^{206} \mathrm{~Pb}$ em zircão entre 1.881 Ma e $1.886 \mathrm{Ma}$ (Tabela 2).

Quimicamente, essas rochas vulcânicas variam de metaluminosas a peraluminosas, apresentando teores elevados de flúor. A caracterização geoquímica detalhada destas unidades, bem como as da Suite Mapuera, está em andamento e serão discutidas pelos autores em trabalhos futuros.

Na região da Província Pitinga, o Grupo Iricoumé é intrudido por oito plutons graníticos distintos. Cinco desses plutons são correlacionados à Suite Mapuera, sendo desprovidos, até o momento, de informações geocronológicas prévias. Os outros três integram a Suite Madeira, mostrando idades entre 1.829 e $1.818 \mathrm{Ma}$ (Costi et al., 2000). Por serem os portadores das mineralizações estaníferas da Província Pitinga, foram intensamente estudados (Carvalho Filho et al., 1984; Daoud \& Antonietto Jr., 1985; Horbe et al., 1985; Macambira et al., 1987; Daoud \& Fuck, 1990; Horbe et al., 1991; Lenharo et al., 1997; Borges, 1997, 2002; Lenharo, 1998; Costi, 2000; Costi et al., 2000).

SUITE MAPUERA Os plutons graníticos relacionados à Suite Mapuera são denominados localmente de Granitos Simão, Rastro, Bom Futuro, Alto Pitinga e Pedreira (Figura 3). Formam corpos mapeáveis na escala adotada no presente trabalho e têm dimensões variando entre 55 e $405 \mathrm{~km}^{2}$. Um outro pluton granítico localizado em área de acesso restrito (Reserva Biológica), no extremo sudeste da província, foi reinterpretado no mapa geológico apresentado pela CPRM em 2002, na escala $1: 1.750 .000$, como pertencente à Suite Mapuera, o que foi mantido neste trabalho (Figura 3).

Granito Simão: apresenta forma alongada na direção NW, com dimensão de $405 \mathrm{~km}^{2}$, é composto por biotita-feldspato alcalino-granito e biotita-sienogranito de cor vermelho escuro a castanho esverdeado e granulação média a grossa. Quimica- 
Tabela 1-Quadro geocronológico regional

Unidade Estratigráfica Idade Método Referência

\section{Complexos do Embasamento e Granitóides da Suite Água Branca}

\begin{tabular}{|c|c|c|c|}
\hline Complexo Anauá - metatonalito & $2028 \pm 9 \mathrm{Ma}$ & $\mathrm{U}-\mathrm{Pb} \mathrm{Zr}^{1}$ & Faria et al. (2002) \\
\hline Suite Água Branca - monzogranito & $1910 \pm 23 \mathrm{Ma}$ & $\mathrm{Rb}-\mathrm{Sr}_{\mathrm{r}}$ & Jorge João et al. (1985) \\
\hline Suite Água Branca - monzogranito & $1951 \mathrm{Ma}$ & $\mathrm{Rb}-\mathrm{Sr}_{\mathrm{r}}$ & Santos \& Reis Neto (1982) \\
\hline Suite Água Branca - monzogranito & $\begin{array}{l}1960 \pm 21 \mathrm{Ma} \\
1938 \pm 37 \mathrm{Ma}\end{array}$ & $\mathrm{U}-\mathrm{Pb} \mathrm{Zr}^{1}$ & Almeida et al. (1997) \\
\hline
\end{tabular}

Rochas vulcânicas - Grupo Iricoumé (Supergrupo Uatumã)

\begin{tabular}{llll}
\hline Grupo Iricoumé - dacito pórfiro & $1893 \pm 2 \mathrm{Ma}$ & $\mathrm{Pb}-\mathrm{Pb} \mathrm{Zr}$ & Macambira et al. (2002) \\
Grupo Iricoumé - riolito pórfiro & $1883 \pm 4 \mathrm{Ma}$ & $\mathrm{Pb}-\mathrm{Pb} \mathrm{Zr}$ & Valério et al. (2005) \\
Grupo Iricoumé - riodacito & $1896 \pm 7 \mathrm{Ma}$ & $\mathrm{Pb}-\mathrm{Pb} \mathrm{Zr^{2 }}$ & Santos et al. (2002a) \\
\hline
\end{tabular}

Granitóides da Suite Mapuera (SG Uatumã) ou mais jovens

\begin{tabular}{llcl}
\hline Charnockito Jaburu & $1873 \pm 6 \mathrm{Ma}$ & U-Pb Zr' & Santos et al. (2001) \\
& $1876 \pm 4 \mathrm{Ma}$ & & \\
Granito Alalaú BR174 (Roraima) & $1879 \pm 3 \mathrm{Ma}$ & U-Pb Zr & Santos et al. (2002a) \\
& $1880 \pm 3 \mathrm{Ma}$ & & \\
Granito Abonari & $1871 \pm 5 \mathrm{Ma}$ & U-Pb Zr & Santos et al. (2002a) \\
Granito gnáissico BR174 (Roraima) & $1868 \pm 8 \mathrm{Ma}$ & U-Pb Zr & Santos et al. (2002a) \\
Granito Moderna (Roraima) & $1867 \pm 15 \mathrm{Ma}$ & Pb-Pb Zr & Santos et al. (1997) \\
\hline
\end{tabular}

'SHRIMP II U-Pb; ${ }^{2207} \mathrm{~Pb} /{ }^{206} \mathrm{~Pb}$ por evaporação em zircão; $\mathbf{Z r}$ zircão; rt rocha total;

mente são rochas peraluminosas que apresentam elevados teores de $\mathrm{SiO}_{2}$ e $\mathrm{F}$.

Granito Rastro: é um stock de aproximadamente $55 \mathrm{~km}^{2}$, de forma sub-circular, composto por sienogranitos ou quartzo-sienitos granofíricos. São rochas de coloração róseo avermelhada clara com granulação seriada de média a grossa. Quimicamente são rochas peraluminosas, apresentando teor de $\mathrm{SiO}_{2}$ moderado a alto.

Granito Bom Futuro: é composto por rochas de cor castanho claro, de textura inequigranular seriada, com granulação variando de fina a média, raramente grossa, por vezes protomiloníticos. Mostram evidências de deformação dúctil-rúptil, na forma de bandas estreitas e descontínuas marcadas por minerais máficos e micáceos. Este pluton apresenta forma irregular, com cerca de $300 \mathrm{~km}^{2}$, onde predominam composições variando de sieno a monzogranitos. Quimicamente é metaluminoso, com teores moderados de $\mathrm{SiO}_{2}$ e alta razão $\mathrm{Rb} / \mathrm{Sr}$.

Granito Pedreira: tem forma alongada no sentido NE e superficie de $66 \mathrm{~km}^{2}$. É composto predominantemente por feldspato alcalino-granito; quimicamente é peraluminoso, mostrando teores elevados de $\mathrm{SiO}_{2}$ e razão $\mathrm{Rb} / \mathrm{Sr}$ também alta.

Granito Alto Pitinga: é um pluton de aproximadamente 121 $\mathrm{km}^{2}$, com contornos irregulares, sendo composto por três fácies petrograficamente distintas e exibindo evidências de processos cataclásticos superimpostos. Quimicamente são peraluminosos ou metaluminosos, mostrando teores altos de $\mathrm{SiO}_{2}$ e álcalis e baixos de $\mathrm{CaO}$. A Fácies 1 (biotita-hornblenda-sienogranito) apresenta cor castanho escuro com manchas e pontuações pretas e esbranquiçadas e textura equigranular de granulação média. A Fácies 2 (biotita-monzogranito) é de cor castanho amarelado com manchas e pontuações pretas, granulação variando de grossa a média, exibindo freqüentemente textura tipo rapakivi. A Fácies 3 (biotita-sienogranito porfirítico) apresenta cor castanho claro com manchas e pontuações verde escuro e esbranquiçadas. Apresenta textura porfirítica com matriz de granulação fina a média e fenocristais de feldspato potássico e quartzo subédricos ou anédricos.

FORMAÇÃO URUPI A Formação Urupi (Veiga Jr. et al., 1979) (Figura 3) é representada por rochas sedimentares clásticas continentais (quartzo-arenitos, arenitos arcoseanos e siltitos), intercaladas por níveis de rochas piroclásticas (tufos silicificados e ignimbritos). Os dados de campo obtidos durante o mapeamento geológico realizado neste trabalho indicam que essas rochas piroclásticas são similares às da Formação Paraíso, sugerindo que, na Província Pitinga, a deposição da Formação Urupi foi concomitante ou penecontemporânea, ao menos em parte, aos estágios finais do evento vulcânico que originou o Grupo Iricoumé na região.

Santos et al. (2002b) apresentam a idade de 1.780 Ma para um diabásio da Formação Quarenta Ilhas, intrusivo na Formação Urupi, o que determina a idade mínima desta unidade na Província Pitinga.

SUITE MADEIRA A Suite Madeira (Figura 3) é representada por plutons graníticos mais jovens, denominados localmente Europa, Água Boa e Madeira, os quais apresentam características mineralógicas e químicas similares as de granitos tipo A (Horbe et al., 1991; Daoud, 1988; Lenharo, 1998; Costi, 2000). 


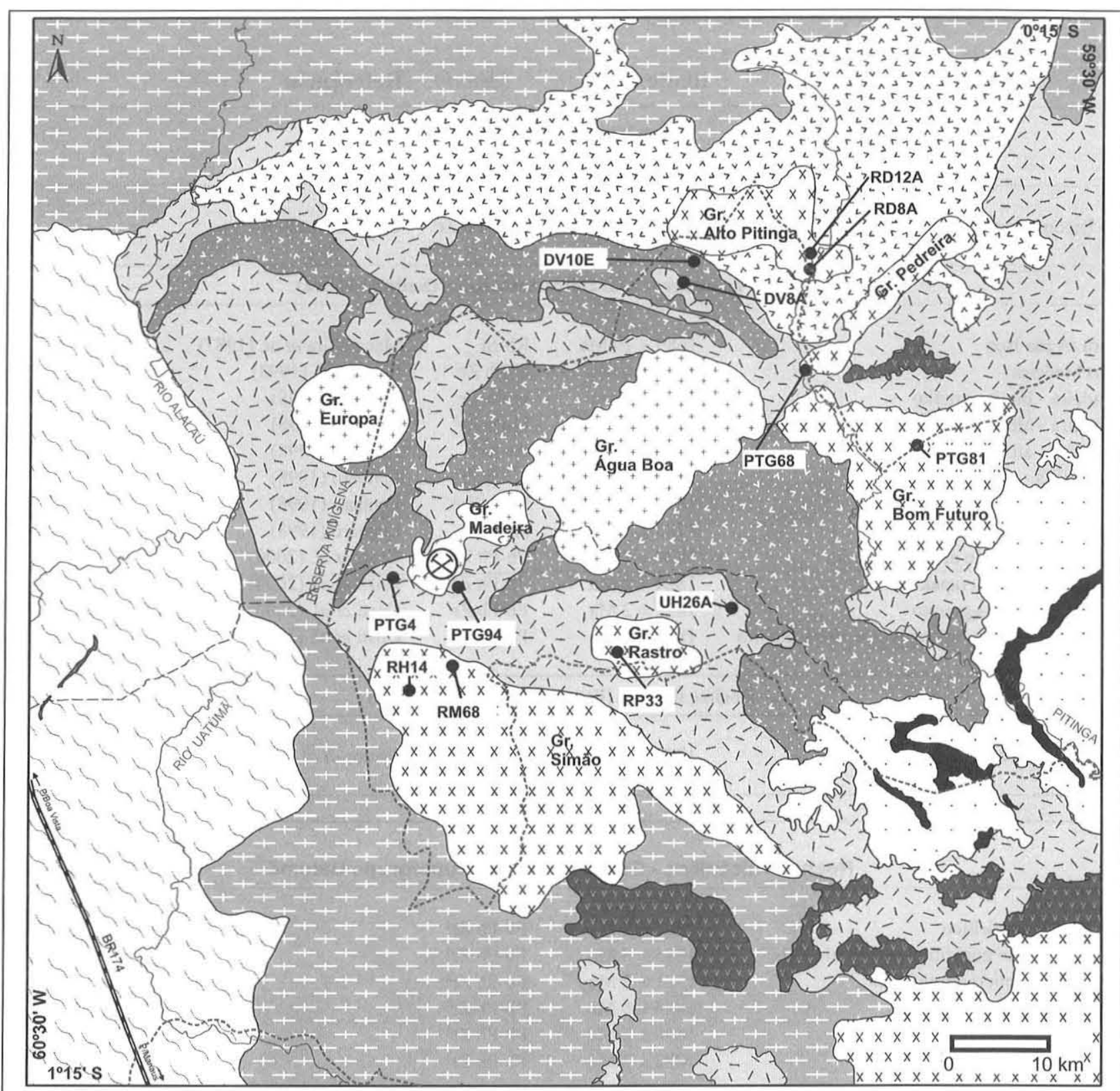

\section{Legenda}

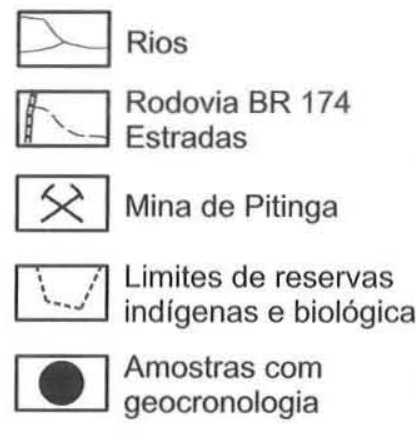

\begin{tabular}{|c|c|c|c|}
\hline \multirow{10}{*}{ 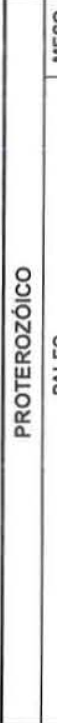 } & \multirow{3}{*}{ 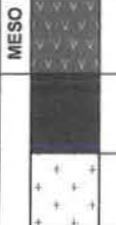 } & Formação Seringa & Basaltos alcalinos, diabásios e gabros \\
\hline & & $\begin{array}{c}\text { Formação } \\
\text { Quarenta llhas }\end{array}$ & $\begin{array}{l}\text { Diabásios, olivina-diabásios toleíticos e rochas } \\
\text { diferenciadas ácidas }\end{array}$ \\
\hline & & Suite Madeira & Sienogranitos e feldspato alcalino granitos \\
\hline & \multirow{5}{*}{ 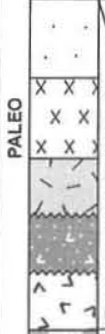 } & Formação Urupi & $\begin{array}{l}\text { Quartzo-arenitos, arcóseos e siltitos com intercalaçōes de } \\
\text { rochas piroclásticas }\end{array}$ \\
\hline & & Suite Mapuera & Sienogranitos a monzogranitos \\
\hline & & : & Riolitos, riodacitos e quatzo-traquitos \\
\hline & & 든 $\mathrm{Fm}$. Paraiso & Tufos e ignimbritos ácidos \\
\hline & & 号荡 Fm. Divisor & Andesitos e latitos porfiriticos \\
\hline & + & $\begin{array}{l}\text { Suite Intrusiva } \\
\text { Agua Branca }\end{array}$ & $\begin{array}{l}\text { Monzogranitos, biotita-monzogranitos, granodioritos, biotita } \\
\text { granodioritos e tonalitos }\end{array}$ \\
\hline & Sis & $\begin{array}{l}\text { Complexo } \\
\text { Guianense }\end{array}$ & $\begin{array}{l}\text { Granitóides foliados, gnaisses e milonitos derivados } \\
\text { de rochas granitóides }\end{array}$ \\
\hline
\end{tabular}

Figura 3 - Mapa geológico e coluna estratigráfica da Província Pitinga 
Tabela 2 - Quadro geocronológico da Provincia Pitinga

Unidade Estratigráfica

Idade

Método Referência

\section{Trabalhos Prévios}

Rochas vulcânicas - Grupo Iricoumé - Supergrupo Uatumã

Grupo Iricoumé - riolito

$1888 \pm 3 \mathrm{Ma}$

$\mathrm{Pb}-\mathrm{Pb} \mathrm{Zr^{ \prime }}$

Costi et al. (2000)

Granitos Estaníferos e Granitos Associados (Suite Madeira)

Madeira /Água Boa

Granito Madeira

Gr. Madeira - biotita-granito

Gr. Madeira - albita-granito

Gr. Madeira - albita-granito

Gr. Água Boa - rapakivi

Gr. Água Boa - topázio-granito

Gr. Água Boa - greisen

Gr. Europa - feldspato alcalino-granito

Gr. Madeira - granito rapakivi

Gr. Madeira - biotita-granito

Gr. Madeira - granito hipersolvus e albita-granito

\begin{tabular}{|c|c|c|}
\hline $1689 \pm 19 \mathrm{Ma}$ & $\mathrm{Rb}-\mathrm{Sr}$ & Macambira et al. (1987) \\
\hline $1834 \pm 6 \mathrm{Ma}$ & U-Pb Zr ${ }^{2}$ & Fuck et al. (1993) \\
\hline $1810 \pm 6 \mathrm{Ma}$ & $\mathrm{U}-\mathrm{Pb} \mathrm{Zr^{3 }}$ & Lenharo (1998) \\
\hline $1794 \pm 19 \mathrm{Ma}$ & U-Pb Zr ${ }^{3}$ & Lenharo (1998) \\
\hline $1782 \pm 4 \mathrm{Ma}$ & $\mathrm{Ar}-\mathrm{Ar}^{4}$ & Lenharo (1998) \\
\hline $1798 \pm 10 \mathrm{Ma}$ & U-Pb $\mathrm{Zr}^{3}$ & Lenharo (1998) \\
\hline $1815 \pm 10 \mathrm{Ma}$ & $\mathrm{U}-\mathrm{Pb} \mathrm{Zr}^{3}$ & Lenharo (1998) \\
\hline $1783 \pm 5 \mathrm{Ma}$ & $\mathrm{Ar}-\mathrm{Ar}{ }^{4}$ & Lenharo (1998) \\
\hline $1829 \pm 1 \mathrm{Ma}$ & $\mathrm{Pb}-\mathrm{Pb} \mathrm{Zr^{1 }}$ & Costi et al. (2000) \\
\hline $1824 \pm 2 \mathrm{Ma}$ & $\mathrm{Pb}-\mathrm{Pb} \mathrm{Zr}^{1}$ & Costi et al. (2000) \\
\hline $1822 \pm 2 \mathrm{Ma}$ & $\mathrm{Pb}-\mathrm{Pb} \mathrm{Zr^{1 }}$ & Costi et al. (2000) \\
\hline $1818 \pm 2 \mathrm{Ma}$ & $\mathrm{Pb}-\mathrm{Pb} \mathrm{Zr^{1 }}$ & Costi et al. (2000) \\
\hline
\end{tabular}

Rochas Básicas (Formação Quarenta Ilhas)

Diabásio (intrusivo na Formação Urupi) $\quad 1780 \pm 3 \mathrm{Ma} \quad$ U-Pb Zr $\quad$ Santos et al. (2002b)

\section{Este Trabalho}

\section{Rochas vulcânicas - Grupo Iricoumé - Supergrupo Uatumã}

PTG4 - riolito porfirítico

PTG68 - riodacito porfiritico cataclástico

PTG94 - riolito microgranofirico

DV8A - riolito porfirítico

DV10E - ignimbrito riolítico

UH26A - riolito porfirítico

\begin{tabular}{|c|c|}
\hline $1882 \pm 2 \mathrm{Ma}$ & $\mathrm{Pb}-\mathrm{Pb} \mathrm{Zr^{1 }}$ \\
\hline $1885 \pm 8 \mathrm{Ma}$ & $\mathrm{Pb}-\mathrm{Pb} \mathrm{Zr^{1 }}$ \\
\hline $1881 \pm 2 \mathrm{Ma}$ & $\mathrm{Pb}-\mathrm{Pb} \mathrm{Zr}^{1}$ \\
\hline $1886 \pm 6 \mathrm{Ma}$ & $\mathrm{Pb}-\mathrm{Pb} \mathrm{Zr}^{\prime}$ \\
\hline $1890 \pm 2 \mathrm{Ma}$ & $\mathrm{Pb}-\mathrm{Pb} \mathrm{Zr}^{1}$ \\
\hline $1882 \pm 2 \mathrm{Ma}$ & $\mathrm{Pb}-\mathrm{Pb} \mathrm{Zr}^{\prime}$ \\
\hline
\end{tabular}

\section{Granitóides da Suite Mapuera - Supergrupo Uatumã}

\begin{tabular}{lcc}
\hline RM68 - Granito Simão (biotita-granito) & $1882 \pm 4 \mathrm{Ma}$ & $\mathrm{Pb}-\mathrm{Pb} \mathrm{Zr}$ \\
$\begin{array}{l}\text { RH14 - Granito Simão } \\
\text { (biotita-feldspato alcalino-granito) }\end{array}$ & $1885 \pm 4 \mathrm{Ma}$ & $\mathrm{Pb}-\mathrm{Pb} \mathrm{Zr}$ \\
$\begin{array}{l}\text { RP } 33 \text { - Granito Rastro } \\
\text { (sienogranito granofírico) }\end{array}$ & $1882 \pm 2 \mathrm{Ma}$ & $\mathrm{Pb}-\mathrm{Pb} \mathrm{Zr}$ \\
$\begin{array}{l}\text { PTG81 - Granito Bom Futuro } \\
\text { (sienogranito protomilonitico) }\end{array}$ & $1882 \pm 3 \mathrm{Ma}$ & $\mathrm{Pb}-\mathrm{Pb} \mathrm{Zr}$ \\
$\begin{array}{l}\text { RD8A - Granito Alto Pitinga } \\
\text { (biotita-monzogranito cataclástico) }\end{array}$ & $1885 \pm 3 \mathrm{Ma}$ & $\mathrm{Pb}-\mathrm{Pb} \mathrm{Zr}$ \\
$\begin{array}{l}\text { RD12A - Granito Alto Pitinga } \\
\text { (biotita-monzogranito) }\end{array}$ & $1888 \pm 3 \mathrm{Ma}$ & $\mathrm{Pb}-\mathrm{Pb} \mathrm{Zr}$ \\
\hline
\end{tabular}

${ }^{1207} \mathrm{~Pb} /{ }^{206} \mathrm{~Pb}$ por evaporação em zircão; ${ }^{2} \mathrm{U}-\mathrm{Pb}$ zircão TIMS; ${ }^{3}$ SHRIMP II U-Pb; ${ }^{4} \mathrm{Ar}-\mathrm{Ar}$ em micas;

$\underline{\mathrm{Zr}}$ zircão; $\underline{\text { rt } \text { rocha total; }}$

O Granito Europa é um pluton de forma arredondada, de cerca de $100 \mathrm{~km}^{2}$, representado por duas fácies com características peralcalinas, ambas compostas essencialmente por feldspato pertítico e quartzo, portanto de caráter hipersolvus, tendo anfibólio alcalino (riebeckita-arfvedsonita) como principal fase acessória (Prado et al., submetido). Uma das fácies apresenta feldspatos potássicos avermelhados, indicando condições oxidantes durante os seus estágios finais de cristalização (Prado et 
al., submetido). A esta fácies estão relacionadas anomalias de $\mathrm{Nb}$ obtidas a partir de amostragens de solo. Dados geocronológicos deste granito apontam idade ${ }^{207} \mathrm{~Pb} /{ }^{206} \mathrm{~Pb}$ em zircão de 1.829 Ma (Costi et al., 2000).

O Granito Madeira é um pluton de cerca de $55 \mathrm{~km}^{2}$, com forma alongada no sentido nordeste, composto por quatro fácies (Costi et al., 2000), sendo uma fácies precoce de caráter metaluminoso, classificada como anfibólio-biotita-sienogranito porfirítico, com textura rapakivi. Esta fácies é cortada por um biotita-feldspato alcalino-granito equigranular de granulação média, de caráter peraluminoso. Essas duas fácies são intrudidas por um stock de cerca de $2 \mathrm{~km}$ de diâmetro, que é composto por outras duas fácies, classificadas como feldspato alcalino-granito porfirítico hipersolvus e albita-granito. $\mathrm{O}$ albita-granito é dividido em subfácies de núcleo, magmático, de caráter peralcalino e portador de criolita, e subfácies de borda, peraluminoso, portador de fluorita, formado por autometassomatismo a partir da subfácies de núcleo (Costi et al., 2000). O stock de albita-granito é mineralizado em Sn, Nb, Ta e F (criolita), apresentando ainda teores anômalos $\mathrm{Zr}$, Th, U, Y, Rb, Li e ETRP.

O Granito Água Boa é um pluton de forma alongada no sentido nordeste com cerca de $316 \mathrm{~km}^{2}$, composto por quatro fácies (Daoud, 1988; Lenharo, 1998). A fácies precoce é constituída por um anfibólio-biotita-sienogranito de granulação média ou grossa, mostrando esparsamente textura tipo rapakivi. A fácies seguinte é um biotita-sienogranito porfirítico, com matriz de granulação fina. Segue-se um biotita-feldspato alcalino-granito equigranular, de tendência hipersolvus. A última fácies é representada por um topázio-granito porfirítico (Lenharo, 1998). As rochas do pluton Agua Boa são alcalinas, geoquimicamente similares a granitos tipo $\mathrm{A}$, apresentando caráter metaluminoso a peraluminoso (Horbe et al., 1991, Lenharo, 1998).

\section{FORMAÇÃO QUARENTA ILHAS A Formação Quarenta} Ilhas (Figura 3) foi definida por Veiga Jr. et al. (1979) como um conjunto de rochas básicas toleiticas representadas por diabásios, gabros, basaltos e rochas diferenciadas hipabissais. As relações de contato das rochas dessa unidade definem seu caráter intrusivo em rochas sedimentares e intercalações piroclásticas da Formação Urupi. A Formação Quarenta Ilhas, com seção tipo na corredeira homônima do médio curso do rio Pitinga, possui como estrutura mais proeminente o Sill Quarenta Ilhas, encaixado concordantemente nas rochas sedimentares e piroclásticas, na região de fechamento oeste da "braquissinclinal" de Pitinga, definida por Mandetta et al. (1974). Dados geocronológicos obtidos por Santos et al. (2002b) apontam idade de 1.780 Ma para esta unidade.

FORMAÇÃO SERINGA O último evento magmático da Província Pitinga ocorre no final do Mesoproterozóico, representado pela Formação Seringa (Veiga Jr et al., 1979). Esta unidade é constituída por derrames e diques de rochas básicas alcalinas, representadas por basaltos e diabásios (Figura 3). Segundo Araújo Neto \& Moreira (1976), essa manifestação básica teria sua origem associada a esforços distensionais ocorridos após o episódio K'Mudku. Esses autores apresentam idade K/Ar de $1.079 \mathrm{Ma}$ e $1.090 \mathrm{Ma}$ para essas rochas.

GEOCRONOLOGIA Os estudos geocronológicos aqui realizados tiveram dois objetivos principais. O primeiro foi verificar se as idades das rochas vulcânicas da Província Pitinga situavam-se dentro de um mesmo intervalo de tempo. O segundo foi a determinação das idades dos plutons Simão, Rastro, Bom Futuro e Alto Pitinga, cuja correlação à Suite Mapuera sempre foi feita com base em critérios interpretativos, obtidos a partir de imagens de sensores remotos.

Foram determinadas as idades ${ }^{207} \mathrm{~Pb} /{ }^{206} \mathrm{~Pb}$ de 12 amostras de rochas graniticas e vulcânicas da região de Pitinga, assim distribuídas (Tabelas 2 e 3 ):

- cinco amostras de rochas vulcânicas de natureza efusiva pertencentes à Formação Ouro Preto, do Grupo Iricoumé, classificadas como riolito porfirítico (PTG4), riolito porfirítico microgranofírico (PTG94), riodacito porfirítico (PTG68), riolito porfirítico (DV8A) e riolito porfirítico (UH26A);

- uma amostra de rocha piroclástica da Formação Paraíso, classificada como ignimbrito riolítico (DV10E);

As demais amostras representam unidades graníticas da Suite Mapuera:

- duas amostras do Granito Simão, compreendendo um biotita-feldspato alcalino-granito (RH14) e um biotita-granito (RM68);

- uma amostra da fácies sienogranito do Granito Rastro (RP33);

- uma amostra da fácies sienogranito do Granito Bom Futuro (PTG81);

- duas amostras da fácies biotita-monzogranito do Granito Alto Pitinga (RD8A e RD12A).

Métodos analíticos Na determinação da idade das rochas graníticas e vulcânicas da Província Pitinga utilizou-se a técnica de evaporação de $\mathrm{Pb}$ em monocristal de zircão em filamento duplo de rênio. As análises foram realizadas no Laboratório de Geologia Isotópica (Pará-Iso), do Centro de Geociências da Universidade Federal do Pará, utilizando-se um espectrômetro de massa por termoionização (TIMS) Finnigan MAT 262.

Os zircões analisados são provenientes de amostras de rochas sã coletadas em afloramentos naturais. Cerca de $2 \mathrm{~kg}$ de rocha por amostra foi britado, moído, peneirado à $<80$ mesh $\mathrm{e}$ concentrado em batéia. $\mathrm{O}$ produto foi submetido a novo peneiramento à $<150$ mesh, e posteriormente processado em bromofórmio e separador magnético isodinâmico Frantz, onde o zircão foi obtido na fração não magnética. A etapa final consistiu de seleção manual de grãos em lupa binocular e lavagem dos mesmos com $\mathrm{HNO}_{3}(50 \%)$ à quente. Na seleção dos zircões deu-se preferência a grãos límpidos com mínimo de inclusões, fraturas ou evidências de metamictização. Os cristais de zircão selecionados são depositados, individualmente, em filamento de rênio em formato de canoa, denominado de filamento de evaporação. Esse filamento é aquecido e o $\mathrm{Pb}$ presente no zircão é evaporado e depositado em outro filamento de rênio (filamento de ionização), situado em frente ao filamento de evaporação.

Em todos os casos estudados foram experimentadas até 3 etapas de aquecimento, com temperaturas entre 1450 e 1550 ${ }^{\circ} \mathrm{C}$, com tempo de evaporação de 3 a 5 minutos para cada etapa. Após cada etapa de evaporação o filamento de ionização é aquecido a temperaturas entre 1050 e $1100{ }^{\circ} \mathrm{C}$, o que ioniza o $\mathrm{Pb}$ nele depositado e possibilita a determinação da sua composição isotópica. A leitura da intensidade das diferentes massas de $\mathrm{Pb}$ é feita de modo dinâmico, utilizando-se o contador de íons do espectrômetro, segundo a seguinte seqüência de massas: 206, 207, 208, 206, 207 e 204.

O cálculo das idades para cada etapa de ionização é obtida a partir das médias das razões ${ }^{207} \mathrm{~Pb} /{ }^{206} \mathrm{~Pb}$ analisadas. Somente foram consideradas no cálculo das idades as razões ${ }^{207} \mathrm{~Pb} /{ }^{206} \mathrm{~Pb}$ 
obtidas nas etapas de evaporação acima de $1450{ }^{\circ} \mathrm{C}$. Os erros são expressos em desvios de $\pm 2 \sigma$. Os resultados obtidos são apresentados a seguir.

\section{RESULTADOS}

\section{Grupo Iricoumé}

FORMAÇÃO OURO PRETO

Amostra PTG94 (riolito porfirítico microgranofirico): seis cristais de zircão foram utilizados no cálculo da idade dessa amostra. Em um dos filamentos referente ao cristal 8, dado ao pequeno tamanho dos grãos, dois cristais foram montados juntos. Os cristais são róseos claros a incolores e transparentes, apresentando poucas inclusões de cores pretas e transparentes, possivelmente de apatita. São cristais prismáticos, com relação comprimento:largura de $2: 1$ a $4: 1$, exibem arestas bem preservadas porém fraturados. Os cristais analisados apresentaram idades ${ }^{207} \mathrm{~Pb} /{ }^{206} \mathrm{~Pb}$ entre 1.877 $\pm 4 \mathrm{Ma}$ e $1.884 \pm 4 \mathrm{Ma}$, com média de $1.881 \pm 2 \mathrm{Ma}$. Essa idade é interpretada como a idade mínima de cristalização dos cristais de zircão da rocha (Figura 4 e Tabela 3).

Amostra PTG4 (riolito porfiritico): utilizou-se quatro cristais de zircão no cálculo da idade desta amostra. São cristais fraturados, com poucas inclusões, de cor levemente amarelada e forma prismática alongada a ligeiramente arredondados, com relação comprimento:largura de $2: 1$. Os cristais analisados apresentaram idades ${ }^{207} \mathrm{~Pb} /{ }^{206} \mathrm{~Pb}$ entre $1.880 \pm 9 \mathrm{Ma}$ e $1.884 \pm 3 \mathrm{Ma}$, com média de $1.882 \pm 2 \mathrm{Ma}$. Essa idade é interpretada como a idade mínima de cristalização dos cristais de zircão da rocha (Figura 5 e Tabela 3 ).

Amostra PTG68 (riodacito porfiritico): foram utilizados quatro cristais de zircão no cálculo da idade desta amostra, sendo que em um dos filamentos referente ao cristal 15 , devido ao tamanho diminuto dos grãos, foram aprisionados 3 cristais menores juntos. Os cristais utilizados apresentam cor caramelo a róseo claro, exibindo a forma de prismas alongados, com relação comprimento: largura de 3:1 (variando de 1:1 a 4:1), em geral fraturados porém com faces preservadas, com poucas inclusões de cores pretas ou transparentes. As idades ${ }^{207} \mathrm{~Pb} /{ }^{206} \mathrm{~Pb}$ obtidas variam entre $1.873 \pm$ $7 \mathrm{Ma}$ e $1.889 \pm 3 \mathrm{Ma}$, com média de $1.885 \pm 8 \mathrm{Ma}$. Essa idade é interpretada como a idade mínima de cristalização dos cristais de zircão da rocha (Figura 6 e Tabela 3).

Amostra DV8A (riolito porfiritico): foram utilizados seis cristais de zircão no cálculo da idade dessa rocha. Os cristais analisados apresentam cor amarelo claro a transparentes, exibindo poucas inclusões alongadas transparentes, possivelmente de apatita. Os cristais de zircão apresentam formas prismáticas bem definidas, pouco fraturados, e relação comprimento:largura em torno de $2: 1$ a $3: 1$. A idade ${ }^{207} \mathrm{~Pb} /{ }^{206} \mathrm{~Pb}$ definida variou entre $1.877 \pm 4 \mathrm{Ma}$ e $1.899 \pm 28 \mathrm{Ma}$, com média de $1.886 \pm 6 \mathrm{Ma}$. Esta idade é interpretada como a idade mínima de cristalização dos cristais de zircão da rocha (Figura 7 e Tabela 3 ).

Amostra UH26A (riolito porfiritico): no cálculo da idade dessa rocha foram utilizados cinco cristais de zircão. São cristais de cor caramelo a amarelo claro ou marron acastanhado quando exibindo efeitos metamícticos, em geral de forma prismática alongada, com relação comprimento:largura de 2:1 a 3:1. Apresentam as arestas bem preservadas, com poucas fraturas, e algumas inclusões alongadas transparentes. Os cristais analisados apresentaram idades variando de $1.880 \pm 3 \mathrm{Ma}$ e $1.884 \pm 2 \mathrm{Ma}$, com média de $1.882 \pm 2 \mathrm{Ma}$. A idade obtida é interpretada como a idade mínima de cristalização dos cristais de zircão da rocha. (Figura 8 e Tabela 3).

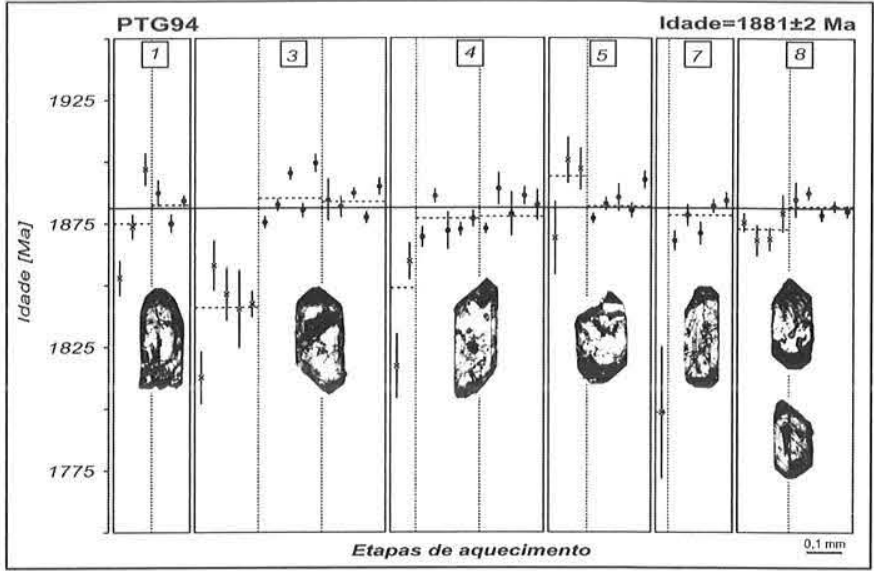

Figura 4-Diagrama de idade $\mathrm{Pb}$-Pb em zircão para a amostra PTG94 (riolito porfiritico microgranofirico). Ordenada: idades (Ma) vs. abscissa: etapas de aquecimento (número do zircão). $[\square$ blocos de razões isotópicas utilizadas; $\square$ bloco eliminado subjetivamente; $x$ bloco eliminado com razão ${ }^{204} \mathrm{~Pb}{ }^{206} \mathrm{~Pb}>$ 0,0004. Desvio analítico de 2 sigma ]

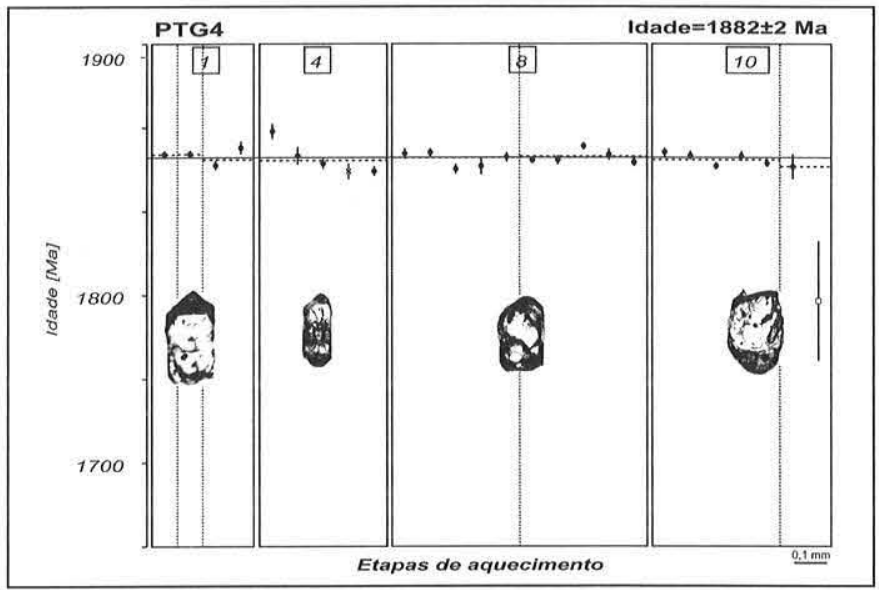

Figura 5 - Diagrama de idade $\mathrm{Pb}$-Pb em zircão para a amostra PTG4 (riolito porfiritico). Legenda: como na figura 4.

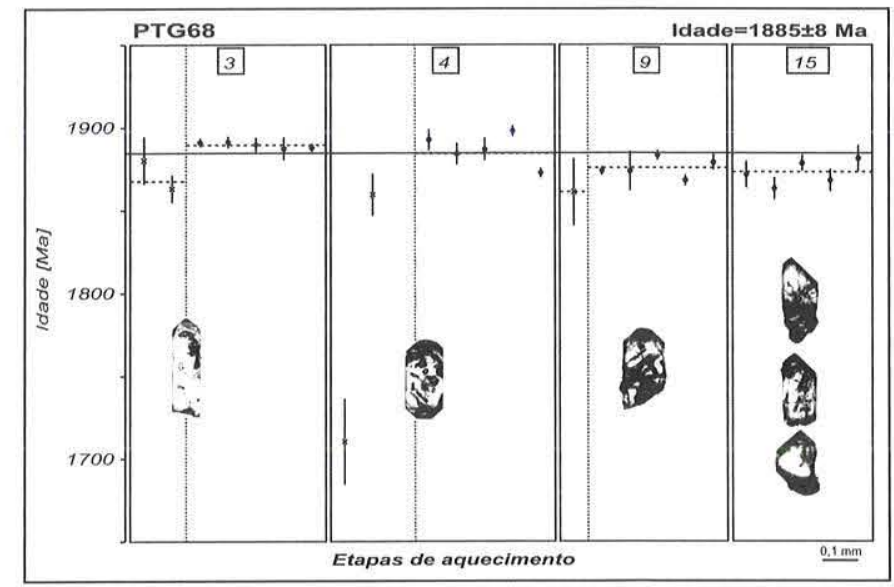

Figura 6-Diagrama de idade $\mathrm{Pb}$-Pb em zircão para a amostra PTG68 (riodacito porfirítico). Legenda: como na figura 4. 


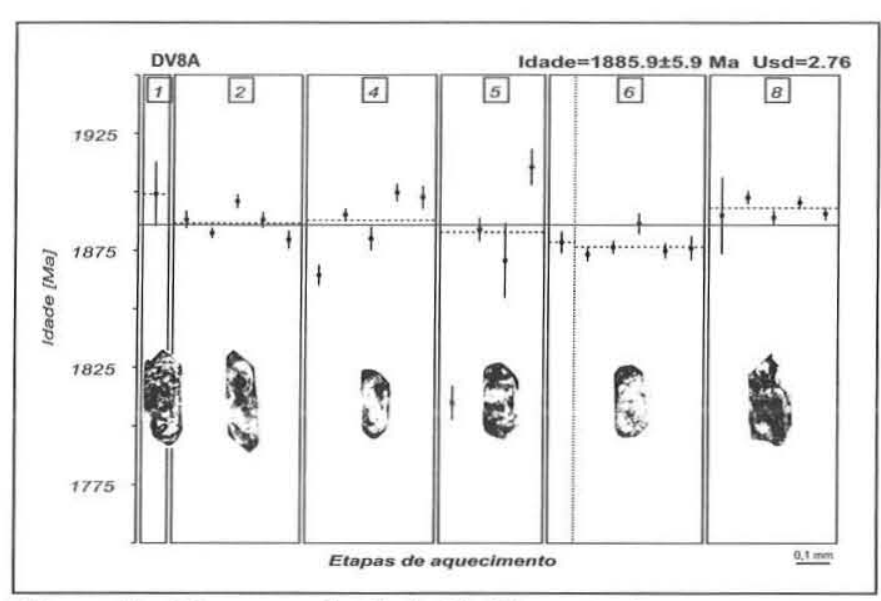

Figura 7 - Diagrama de idade $\mathrm{Pb}$-Pb em zircão para a amostra DV8A (riolito porfiritico). Legenda: como na figura 4.

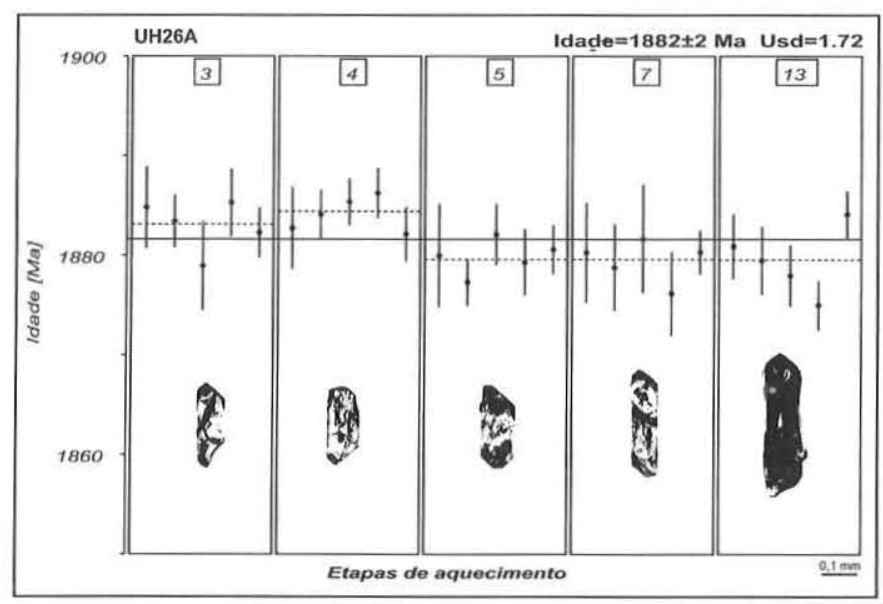

Figura 8-Diagrama de idade $\mathrm{Pb}$-Pb em zircão para a amostra UH26A (riolito porfirítico). Legenda: como na figura 4.

\section{FORMAÇÃO PARAÍSO}

Amostra DV10E (Ignimbrito riolítico): utilizou-se seis cristais de zircão na determinação da idade dessa rocha. São cristais de cor marron muito claro a transparentes, exibindo poucas inclusões arredondadas incolores. São prismas curtos com relação comprimento:largura de 2:1, em geral apresentando faces bem preservadas e pouco fraturados. As idades ${ }^{207} \mathrm{~Pb} /{ }^{206} \mathrm{~Pb}$ obtidas variam de $1.886 \pm 8 \mathrm{Ma}$ e $1893 \pm 6 \mathrm{Ma}$, com média de $1.890 \pm 2 \mathrm{Ma}$. Essa idade é interpretada como a idade mínima de cristalização dos cristais de zircão da rocha (Figura 9 e Tabela 3 ).

\section{Suite Mapuera \\ GRANITO SIMÃO}

Amostra RM68 (anfibólio-biotita-granito): para o cálculo da idade dessa rocha foram utilizados dois cristais de zircão. São zircões transparentes de cor amarelo claro, euédricos, com faces e arestas bem preservadas, mostrando inclusões pretas de granulação muito fina. A relação comprimento:largura é em média 2:1 a 2,5:1. Os cristais analisados apresentaram idades ${ }^{207} \mathrm{~Pb} /{ }^{206} \mathrm{~Pb}$ entre $1.882 \pm 5 \mathrm{Ma}$ e $1.881 \pm 6 \mathrm{Ma}$, com média de $1.882 \pm 4 \mathrm{Ma}$. Essa idade é interpretada como a idade mínima de cristalização da rocha (Figura 10 e Tabela 4).

Amostra RH14 (biotita-feldspato alcalino-granito): a idade dessa amostra foi determinada a partir da análise de 6 cristais de zircão de cor amarelo rosado claro, alguns com pequenas inclusões

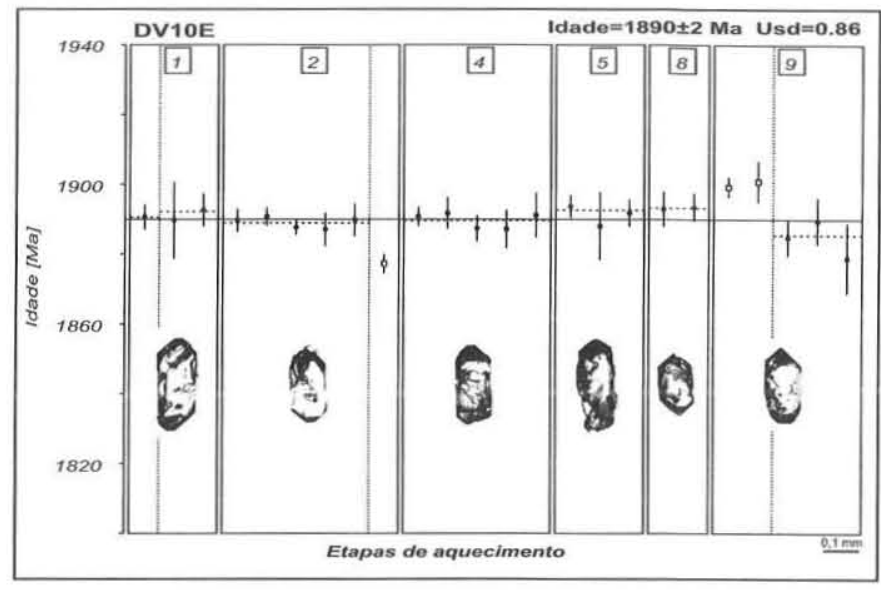

Figura 9-Diagrama de idade $\mathrm{Pb}$ - Pb em zircão para a amostra DVIOE (ignimbrito riolítico). Legenda: como na figura 4.

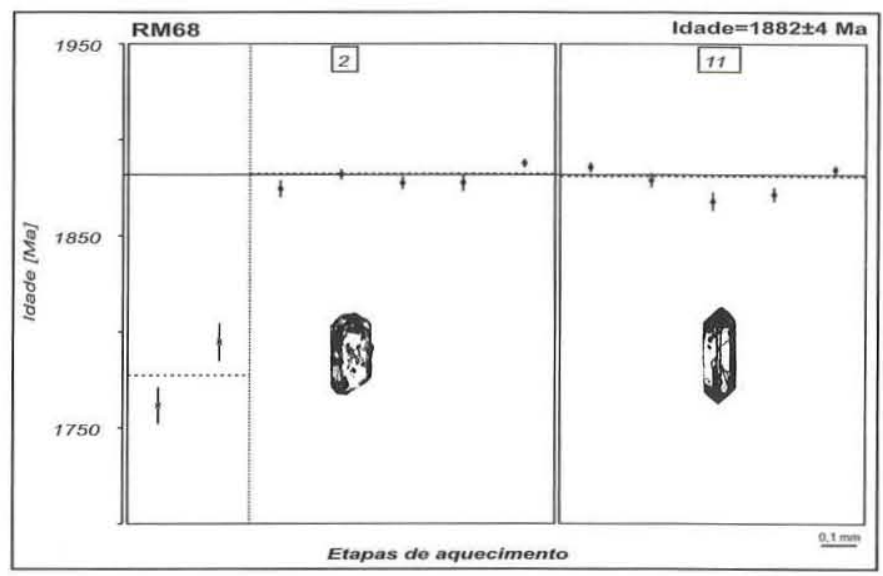

Figura 10-Diagrama de idade $\mathrm{Pb}$ - $\mathrm{Pb}$ em zircão para a amostra RM68 (anfibólio-biotita-granito). Legenda: como na figura 4.

de cor preta ou transparentes. A relação comprimento:largura é em média 2:1 a 1,5:1, e em geral estão quebrados, mas com faces e arestas preservadas. Alguns cristais exibem leve efeito metamíctico. As idades ${ }^{207} \mathrm{~Pb} /{ }^{206} \mathrm{~Pb}$ obtidas variam entre $1.864 \pm$ $26 \mathrm{Ma}$ e $1.891 \pm 5 \mathrm{Ma}$, com média de $1.885 \pm 4 \mathrm{Ma}$. Essa idade é interpretada como a idade mínima de cristalização da rocha (Figura 11 e Tabela 4).

\section{GRANITO RASTRO}

Amostra RP33 (sienogranito): a idade da rocha foi obtida a partir da análise de quatro cristais de zircão. São cristais de cor caramelo claro a róseos, transparentes, a maioria com arestas abrasadas, em geral fraturados e eventualmente exibindo inclusões de cores claras. Alguns cristais exibem efeitos metamícticos. Em geral apresentam formas de prismas curtos, com relação comprimento:largura de 1:1 a 2:1. Os cristais analisados apresentaram idades ${ }^{207} \mathrm{~Pb} /{ }^{206} \mathrm{~Pb}$ entre $1.879 \pm 4 \mathrm{Ma}$ e $1.886 \pm$ $8 \mathrm{Ma}$, com média de $1.882 \pm 2 \mathrm{Ma}$. Essa idade é interpretada como a idade mínima de cristalização da rocha (Figura 12 e Tabela 4).

\section{GRANITO BOM FUTURO}

Amostra PTG81 (sienogranito): a idade dessa fácies foi obtida a partir da análise de oito cristais de zircão. São cristais de cor amarelo claro a róseos, transparentes, exibindo a forma de prismas alongados, com relação comprimento:largura de $2: 1$ a 3:1. 
Geologia e geocronologia Pb-Pb de rochas graníticas e vulcânicas ácidas a intermediárias Paleoproterozóicas da Provincia Pitinga, Craton Amazônico

Tabela 3 - Idades ${ }^{207} \mathrm{~Pb}{ }^{206} \mathrm{~Pb}$ em zircão de rochas vulcânicas do Grupo Iricoumé na Provincia Pitinga

\begin{tabular}{|c|c|c|c|c|c|c|c|c|c|c|c|}
\hline Zircao & Razőes & ${ }^{204} \mathrm{~Pb} /{ }^{206} \mathrm{~Pb}$ & $2 \sigma$ & ${ }^{208} \mathrm{~Pb} /{ }^{206} \mathrm{~Pb}$ & $2 \sigma$ & ${ }^{207} \mathrm{~Pb} /{ }^{206} \mathrm{~Pb}$ & $2 \sigma$ & $\left({ }^{207} \mathrm{~Pb} /{ }^{206} \mathrm{~Pb}\right) \mathrm{c}$ & $2 \sigma$ & Idade & $2 \sigma$ \\
\hline \multicolumn{12}{|c|}{ Supergrupo Uatumã - Grupo Iricoumé - Formação Ouro Preto (PTG94 - Riolito porfiritico microgranofirico) $1.881 \pm 2 \mathrm{Ma}$} \\
\hline PTG94/1 & $24 / 48$ & 0.000075 & 0.000007 & 0.18523 & 0.00184 & 0.11624 & 0.00027 & 0.11514 & 0.00038 & 1883 & 6 \\
\hline PTG94/3 & $70 / 104$ & 0.000088 & 0.000015 & 0.15263 & 0.01054 & 0.11654 & 0.00027 & 0.11525 & 0.00028 & 1884 & 4 \\
\hline PTG94/4 & $74 / 88$ & 0.000263 & 0.000018 & 0.17818 & 0.01165 & 0.11937 & 0.00114 & 0.11483 & 0.00029 & 1877 & 4 \\
\hline PTG94/5 & $34 / 54$ & 0.000141 & 0.000009 & 0.20451 & 0.00077 & 0.11720 & 0.00026 & 0.11510 & 0.00033 & 1882 & 5 \\
\hline PTG94/7 & $40 / 48$ & 0.000140 & 0.000007 & 0.17662 & 0.00049 & 0.11673 & 0.00038 & 0.11489 & 0.00039 & 1878 & 6 \\
\hline PTG94/8 & $34 / 60$ & 0.000122 & 0.000004 & 0.18695 & 0.00129 & 0.11678 & 0.00024 & 0.11510 & 0.00020 & 1882 & 3 \\
\hline Média & $276 / 402$ & & & & & & & Idade Média & s grảos = & 1881 & 2 \\
\hline \multicolumn{12}{|c|}{ Supergrupo Uatumã - Grupo Iricoumé - Formação Ouro Preto (PTG4 - Riolito porfiritico) $1.882 \pm 2 \mathrm{Ma}$} \\
\hline PTG4/1 & $30 / 30$ & 0.000001 & 0.000007 & 0.16156 & 0.00863 & 0.11539 & 0.00026 & 0.11522 & 0.00020 & 1884 & 3 \\
\hline PTG4/4 & $28 / 54$ & 0.000568 & 0.000016 & 0.14569 & 0.00069 & 0.12274 & 0.00050 & 0.11501 & 0.00060 & 1880 & 9 \\
\hline PTG4/8 & $78 / 78$ & 0.000038 & 0.000071 & 0.17156 & 0.00266 & 0.11573 & 0.00087 & 0.11514 & 0.00018 & 1882 & 3 \\
\hline PTG4/10 & $48 / 56$ & 0.000020 & 0.000007 & 0.16703 & 0.00660 & 0.11532 & 0.00016 & 0.11504 & 0.00020 & 1881 & 3 \\
\hline Média & $184 / 342$ & & & & & & & Idade Média c & s grăos = & 1882 & 2 \\
\hline \multicolumn{12}{|c|}{ Supergrupo Uatumã - Grupo Iricoumé - Formação Ouro Preto (PTG68 - Riodacito porfiritico) $1.885 \pm 8 \mathrm{Ma}$} \\
\hline PTG68/3 & $36 / 36$ & 0.000049 & 0.000008 & 0.44653 & 0.00801 & 0.11628 & 0.00018 & 0.11560 & 0.00019 & 1889 & 3 \\
\hline PTG68/4 & $28 / 28$ & 0.000341 & 0.000011 & 0.19261 & 0.00081 & 0.11953 & 0.00065 & 0.11526 & 0.00071 & 1884 & 11 \\
\hline PTG68/9 & $34 / 34$ & 0.000101 & 0.000024 & 0.15603 & 0.00055 & 0.11615 & 0.00020 & 0.11471 & 0.00035 & 1876 & 6 \\
\hline PTG68/15 & $38 / 38$ & 0.000211 & 0.000046 & 0.19037 & 0.00233 & 0.11722 & 0.00057 & 0.11456 & 0.00042 & 1873 & 7 \\
\hline Média & $136 / 144$ & & & & & & & Idade Média c & s grãos = & 1885 & 8 \\
\hline \multicolumn{12}{|c|}{ Supergrupo Uatumã - Grupo Iricoumé - Formação Ouro Preto (DV08A - Riolito porfirítico) $1.886 \pm 6 \mathrm{Ma}$} \\
\hline DV8A/1 & $6 / 10$ & 0.000071 & 0.000082 & 0.14845 & 0.00327 & 0.11716 & 0.00142 & 0.11621 & 0.00180 & 1899 & 28 \\
\hline DV8A/2 & $36 / 54$ & 0.000064 & 0.000002 & 0.17728 & 0.00076 & 0.11631 & 0.00040 & 0.11541 & 0.00036 & 1887 & 6 \\
\hline DV8A/4 & $32 / 32$ & 0.000277 & 0.000025 & 0.15198 & 0.00223 & 0.11925 & 0.00076 & 0.11550 & 0.00075 & 1888 & 12 \\
\hline DV8A/5 & $22 / 38$ & 0.000444 & 0.000031 & 0.14335 & 0.00127 & 0.12163 & 0.00147 & 0.11567 & 0.00118 & 1891 & 18 \\
\hline DV8A/6 & $38 / 38$ & 0.000144 & 0.000089 & 0.14780 & 0.00067 & 0.11717 & 0.00136 & 0.11479 & 0.00023 & 1877 & 4 \\
\hline DV08/8 & $38 / 38$ & 0.000319 & 0.000011 & 0.16057 & 0.00050 & 0.12023 & 0.00018 & 0.11584 & 0.00022 & 1893 & 3 \\
\hline Média & $172 / 210$ & & & & & & & Idade Média & s grãos = & 1886 & 6 \\
\hline \multicolumn{12}{|c|}{ Supergrupo Uatumä - Grupo Iricoumé - Formação Ouro Preto (UH26A - Riolito porfiritico) $1.882 \pm 2 \mathrm{Ma}$} \\
\hline $\mathrm{UH} 26 \mathrm{a} / 3$ & $40 / 40$ & 0.000105 & 0.000001 & 0.15988 & 0.00058 & 0.11645 & 0.00018 & 0.11518 & 0.00018 & 1883 & 3 \\
\hline $\mathrm{UH} 26 \mathrm{a} / 4$ & $30 / 30$ & 0.000047 & 0.000004 & 0.19217 & 0.00094 & 0.11603 & 0.00018 & 0.11527 & 0.00015 & 1884 & 2 \\
\hline UH26a/5 & $34 / 34$ & 0.000281 & 0.000007 & 0.16458 & 0.00008 & 0.11898 & 0.00029 & 0.11497 & 0.00017 & 1880 & 3 \\
\hline $\mathrm{UH} 26 \mathrm{a} / 7$ & $38 / 38$ & 0.000100 & 0.000002 & 0.16886 & 0.00085 & 0.11637 & 0.00018 & 0.11497 & 0.00021 & 1880 & 3 \\
\hline UH26a/13 & $28 / 36$ & 0.000144 & 0.000008 & 0.18331 & 0.00052 & 0.11702 & 0.00019 & 0.11507 & 0.00019 & 1881 & 3 \\
\hline Média & $170 / 178$ & & & & & & & Idade Média & s grãos = & 1882 & 2 \\
\hline \multicolumn{12}{|c|}{ Supergrupo Uatumã - Grupo Iricoumé - Formaçăo Paraiso (DV10e - Ignimbrito riolitico) $1.890 \pm 2$} \\
\hline DV10E/1 & $24 / 24$ & 0.000048 & 0.000084 & 0.20696 & 0.01737 & 0.11671 & 0.00152 & 0.11571 & 0.00036 & 1891 & 6 \\
\hline DV10E/2 & $40 / 48$ & 0.000016 & 0.000006 & 0.20256 & 0.00059 & 0.11587 & 0.00018 & 0.11556 & 0.00018 & 1889 & 3 \\
\hline DV10E/4 & $38 / 38$ & 0.000203 & 0.000014 & 0.20944 & 0.00116 & 0.11825 & 0.00027 & 0.11561 & 0.00024 & 1890 & 4 \\
\hline DV10E/5 & $16 / 16$ & 0.000039 & 0.000007 & 0.18923 & 0.00152 & 0.11630 & 0.0003 & 0.11580 & 0.00032 & 1893 & 5 \\
\hline DV10E/8 & $14 / 14$ & 0.000207 & 0.000013 & 0.22008 & 0.00167 & 0.11860 & 0.00036 & 0.11584 & 0.00041 & 1893 & 6 \\
\hline DV10E/9 & $22 / 34$ & 0.000163 & 0.000053 & 0.22896 & 0.00192 & 0.11827 & 0.00048 & 0.11534 & 0.00049 & 1886 & 8 \\
\hline Média & $154 / 174$ & & & & & & & \multicolumn{2}{|c|}{ Idade Média dos grãos = } & 1890 & 2 \\
\hline
\end{tabular}

Apresentam fraturas irregulares, com a maioria das faces preservadas e também algumas inclusões transparentes alongadas ou de minerais opacos. As idades ${ }^{207} \mathrm{~Pb} /{ }^{206} \mathrm{~Pb}$ obtidas variam entre $1.876 \pm 6 \mathrm{Ma}$ e $1.886 \pm 2 \mathrm{Ma}$, com média de $1.882 \pm 3 \mathrm{Ma}$. Essa idade é interpretada como a idade mínima de cristalização da rocha (Figura 13 e Tabela 4 ).

\section{GRANITO ALTO PITINGA}

Amostra RD12A (biotita-monzogranito): no cálculo da idade dessa fácies foram utilizados sete cristais de zircão. Os cristais utilizados apresentam cores marrom claro a caramelo, são cristais subédricos, com faces parcialmente preservadas, exibem forma de prismas curtos com relação comprimento:largura de $2: 1$ a $3: 1$, alguns apresentando efeitos metamícticos. Apresentam poucas inclusões de cor preta com formas arredondadas e transparentes com formas alongadas. As idades ${ }^{207} \mathrm{~Pb} /{ }^{206} \mathrm{~Pb}$ obtidas variam entre $1.876 \pm 6 \mathrm{Ma}$ e $1.896 \pm 7 \mathrm{Ma}$, com média de $1.886 \pm 3 \mathrm{Ma}$. Essa idade é interpretada como a idade mínima de cristalização da rocha (Figura 14 e Tabela 4).

Amostra RD8A (biotita-monzogranito): o cálculo da idade dessa amostra foi feito a partir da análise isotópica de seis cristais de zircão, sendo que em um dos spots (cristal 6), devido ao tamanho diminuto dos grãos, foram aprisionados 3 cristais menores juntos. São cristais transparentes a levemente amarelados, com inclusões pretas arredondadas. Apresentam a forma de prismas curtos, com faces bem preservadas angulosos, por vezes quebradas, com relação comprimento:largura variando de $1: 1$ a $3: 1$. Os resultados obtidos apontam idades no variando entre $1.882 \pm 3 \mathrm{Ma}$ e $1.894 \pm 10 \mathrm{Ma}$, com média de $1.888 \pm 3$ 


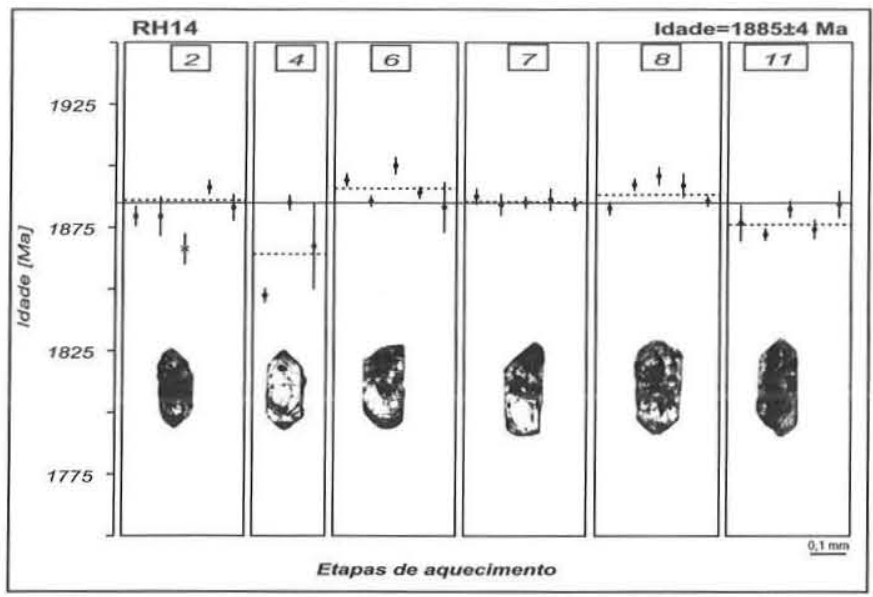

Figura 11 - Diagrama de idade Pb-Pb em zircão para a amostra RH14 (biotita-feldspato alcalino-granito). Legenda: como na figura 4.

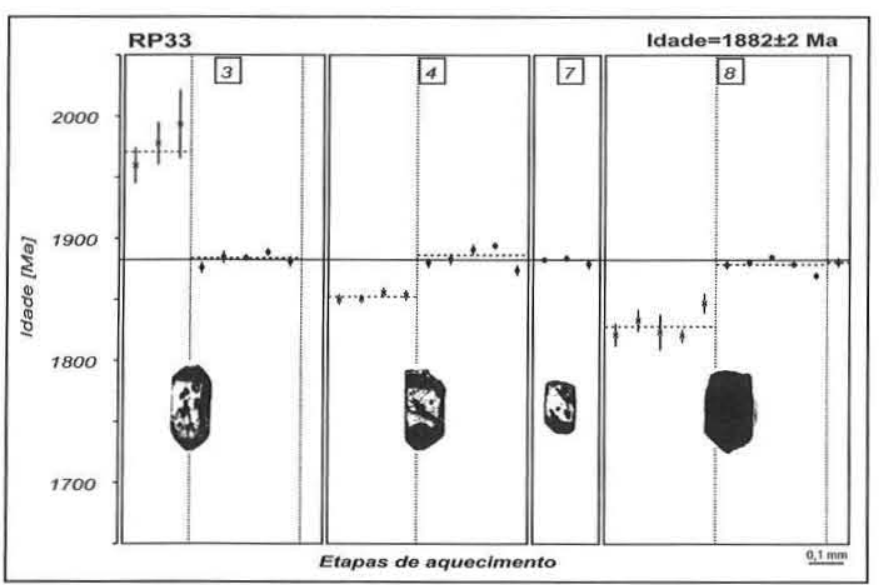

Figura 12 - Diagrama de idade $\mathrm{Pb}-\mathrm{Pb}$ em zircão para a amostra RP33 (sienogranito). Legenda: como na figura 4.

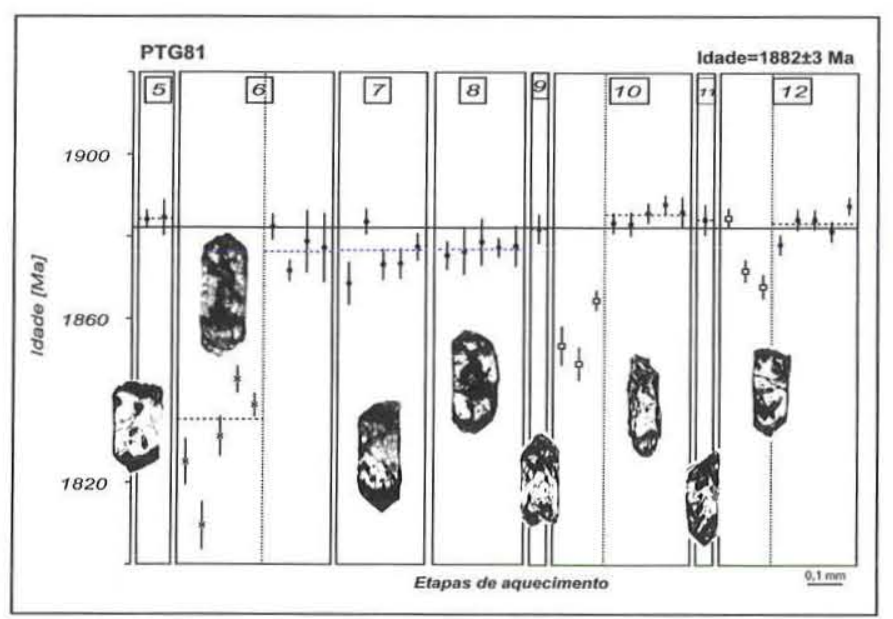

Figura 13 - Diagrama de idade $\mathrm{Pb}$-Pb em zircão para a amostra PTG81 (sienogranito). Legenda: como na figura 4.

Ma. Essa idade é interpretada como a idade mínima de cristalização da rocha (Figura 15 e Tabela 4).

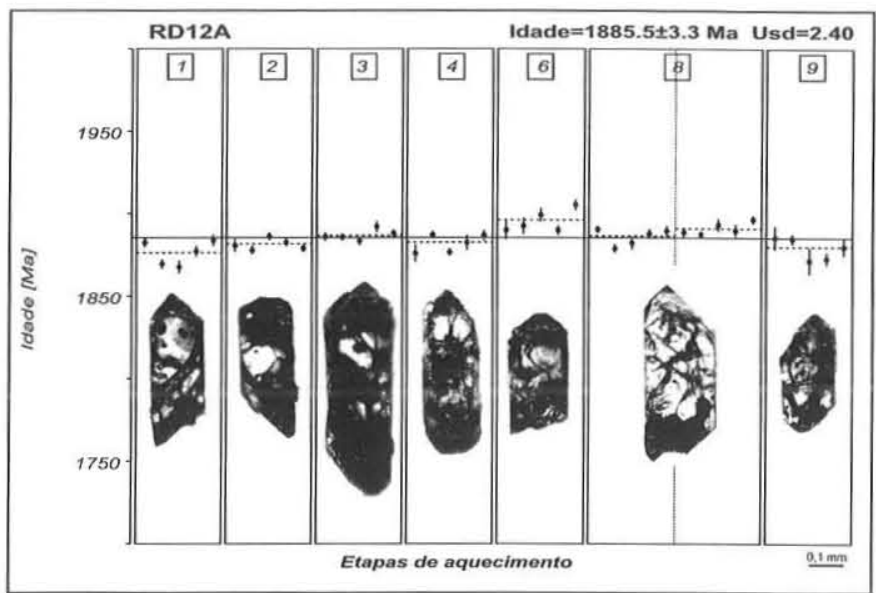

Figura 14 - Diagrama de idade Pb-Pb em zircão para a amostra RD12A (biotita-monzogranito). Legenda: como na figura 4.

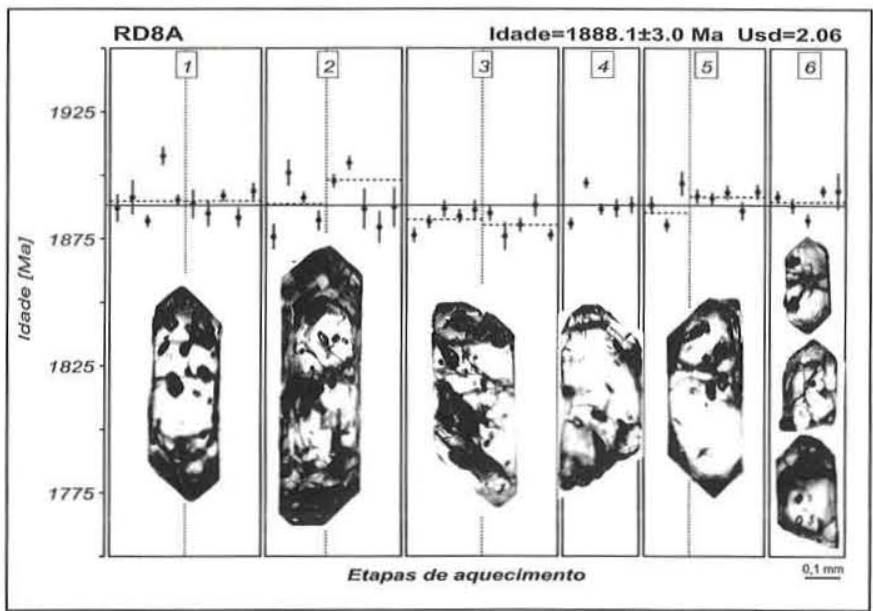

Figura 15 - Diagrama de idade Pb-Pb em zircão para a amostra RD8A (biotita-monzogranito). Legenda: como na figura 4

DISCUSSÃO O vulcanismo paleoproterozóico registrado no craton Amazônico, que ainda hoje é indiscriminadamente atribuído ao Supergrupo Uatumã, de Melo et al. (1978), tem ampla distribuição regional e abrange diversas manifestações vulcânicas, às quais podem associar-se diversas suites de rochas granitóides epizonais. Atualmente, na porção do craton situado a norte da bacia paleozóica do Amazonas, o Supergrupo Uatumã é definido como formado por dois grupos de rochas vulcânicas. A primeira - Grupo Iricoumé - compreende predominantemente vulcânicas ácidas com idades próximas de $1.88 \mathrm{Ga}$, ocorre em uma larga faixa que se estende desde a borda da bacia paleozóica até o sul do estado de Roraima. A segunda unidade - Grupo Surumu - compreende rochas vulcânicas intermediárias e ácidas com idades entre 1.96 e $2.04 \mathrm{Ga}$, e ocorre principalmente a norte, nos estados de Roraima e Pará. A sul da bacia paleozóica, na província aurífera do Tapajós, o Supergrupo Uatumã também é representado por unidades vulcânicas ácidas, pertencentes à Formação Moraes Almeida (1.89-1.87 Ga) e por vulcânicas intermediárias, mais antigas, pertencentes à Formação Vila Riozinho com idades entre 1.97 e $2.0 \mathrm{Ga}$, ambas definidas por Lamarão et al. (2002) e enquadradas no Grupo Iriri.

Em função do amplo espectro de critérios usados em sua caracterização, e da elasticidade em sua aplicação, a definição atualmente empregada para o Supergrupo Uatumã reúne, em 
Geologia e geocronologia Pb-Pb de rochas graníticas e vulcânicas ácidas a intermediárias Paleoproterozóicas da Provincia Pitinga, Craton Amazônico

Tabela 4 - Idades ${ }^{207} \mathrm{~Pb}{ }^{206} \mathrm{~Pb}$ em zircão de rochas graniticas da Suite Mapuera na Província Pitinga

\begin{tabular}{|c|c|c|c|c|c|c|c|c|c|c|c|}
\hline Zircão & Razöes & ${ }^{204} \mathrm{~Pb} /{ }^{206} \mathrm{~Pb}$ & $2 \sigma$ & ${ }^{208} \mathrm{~Pb} /{ }^{206} \mathrm{~Pb}$ & $2 \sigma$ & ${ }^{207} \mathrm{~Pb} /{ }^{206} \mathrm{~Pb}$ & $2 \sigma$ & $\left({ }^{207} \mathrm{~Pb} /{ }^{206} \mathrm{~Pb}\right) \mathrm{c}$ & $2 \sigma$ & Idade & $2 \sigma$ \\
\hline \multicolumn{12}{|c|}{ Supergrupo Uatumã - Suite Intrusiva Mapuera - Granito Simão (RM68 - Biotita granito) $1.882 \pm 4$ Ma } \\
\hline RM68/2 & $36 / 36$ & 0.000126 & 0.000004 & 0.17148 & 0.00057 & 0.11693 & 0.00029 & 0.11514 & 0.00031 & 1882 & 5 \\
\hline RM68/11 & $34 / 34$ & 0.000022 & 0.000017 & 0.16360 & 0.00122 & 0.11584 & 0.00060 & 0.11506 & 0.00039 & 1881 & 6 \\
\hline Média & $70 / 70$ & & & & & & & \multicolumn{2}{|c|}{ Idade Média dos grãos = } & 1882 & 4 \\
\hline \multicolumn{12}{|c|}{ Supergrupo Uatumã - Suite Intrusiva Mapuera - Granito Simão (RH14 - Biotita-feldspato alcalino-granito) $1.885 \pm 4$ Ma } \\
\hline $\mathrm{RH} 14 / 2$ & $28 / 36$ & 0.000472 & 0.000044 & 0.16372 & 0.00163 & 0.12118 & 0.00112 & 0.11538 & 0.00040 & 1886 & 6 \\
\hline $\mathrm{RH} 14 / 4$ & $18 / 18$ & 0.000150 & 0.000068 & 0.14820 & 0.00089 & 0.11601 & 0.00103 & 0.11399 & 0.00166 & 1864 & 26 \\
\hline $\mathrm{RH} 14 / 6$ & $34 / 34$ & 0.000045 & 0.000004 & 0.16677 & 0.00119 & 0.11627 & 0.00032 & 0.11567 & 0.00031 & 1891 & 5 \\
\hline $\mathrm{RH} 14 / 7$ & $40 / 40$ & 0.000061 & 0.000005 & 0.15634 & 0.00138 & 0.11603 & 0.00018 & 0.11531 & 0.00019 & 1885 & 3 \\
\hline $\mathrm{RH} 14 / 8$ & $40 / 40$ & 0.000033 & 0.000011 & 0.13457 & 0.00033 & 0.11605 & 0.00039 & 0.11549 & 0.00029 & 1888 & 5 \\
\hline RH14/11 & $36 / 36$ & 0.000099 & 0.000013 & 0.13946 & 0.00108 & 0.11613 & 0.00021 & 0.11472 & 0.00030 & 1876 & 5 \\
\hline Média & $196 / 204$ & & & & & & & Idade Média & s grăos = & 1885 & 4 \\
\hline \multicolumn{12}{|c|}{ Supergrupo Uatumã - Suite Intrusiva Mapuera - Granito Rastro (RP33 - Sienogranito) $1.882 \pm 2 \mathrm{Ma}$} \\
\hline RP33/3 & $38 / 66$ & 0.000211 & 0.000015 & 0.17850 & 0.00054 & 0.11810 & 0.00017 & 0.11524 & 0.00025 & 1884 & 4 \\
\hline RP33/4 & $32 / 54$ & 0.000144 & 0.000011 & 0.15263 & 0.00094 & 0.11731 & 0.00024 & 0.11540 & 0.00049 & 1886 & 8 \\
\hline RP33/7 & $20 / 20$ & 0.000080 & 0.000002 & 0.17270 & 0.00051 & 0.11623 & 0.00020 & 0.11515 & 0.00021 & 1883 & 3 \\
\hline RP33/8 & $36 / 76$ & 0.000067 & 0.000005 & 0.17304 & 0.03101 & 0.11589 & 0.00019 & 0.11494 & 0.00027 & 1879 & 4 \\
\hline Média & $126 / 216$ & & & & & & & Idade Média & s grãos = & 1882 & 2 \\
\hline \multicolumn{12}{|c|}{ Supergrupo Uatumã - Suite Intrusiva Mapuera - Granito Bom Futuro (PTG81 - Sienogranito protomilonitico) $1.886 \pm 3$ Ma } \\
\hline PTG81/5 & $12 / 12$ & 0.000093 & 0.000022 & 0.16590 & 0.00386 & 0.11658 & 0.00045 & 0.11526 & 0.00027 & 1884 & 4 \\
\hline PTG81/6 & $26 / 26$ & 0.000046 & 0.000005 & 0.18257 & 0.00066 & 0.11551 & 0.00053 & 0.11475 & 0.00037 & 1876 & 6 \\
\hline PTG81/7 & $36 / 36$ & 0.000106 & 0.000004 & 0.18150 & 0.00053 & 0.11615 & 0.00028 & 0.11478 & 0.00032 & 1877 & 5 \\
\hline PTG81/8 & $36 / 36$ & 0.000080 & 0.000006 & 0.15688 & 0.00074 & 0.11587 & 0.00020 & 0.11480 & 0.00021 & 1877 & 3 \\
\hline PTG81/9 & $8 / 8$ & 0.000038 & 0.000028 & 0.17058 & 0.00196 & 0.11562 & 0.00028 & 0.11511 & 0.00047 & 1882 & 7 \\
\hline PTG81/10 & $32 / 32$ & 0.000037 & 0.000004 & 0.16210 & 0.00042 & 0.11579 & 0.00015 & 0.11534 & 0.00015 & 1886 & 2 \\
\hline PTG81/11 & $8 / 8$ & 0.000059 & 0.000006 & 0.18409 & 0.00019 & 0.11605 & 0.00047 & 0.11526 & 0.00048 & 1884 & 7 \\
\hline PTG81/12 & $38 / 38$ & 0.000034 & 0.000007 & 0.16483 & 0.00039 & 0.11570 & 0.00014 & 0.11520 & 0.00021 & 1883 & 3 \\
\hline Média & $196 / 196$ & & & & & & & Idade Média & s grãos = & 1882 & 3 \\
\hline \multicolumn{12}{|c|}{ Supergrupo Uatumä - Suite Intrusiva Mapuera - Granito Alto Pitinga (RD12A - Biotita-monzogranito) $1.886 \pm 3 \mathrm{Ma}$} \\
\hline RD12A1 & $34 / 66$ & 0.000131 & 0.000006 & 0.17607 & 0.00059 & 0.11672 & 0.00056 & 0.11476 & 0.00041 & 1876 & 6 \\
\hline $\mathrm{RD} 12 \mathrm{~A} / 2$ & $36 / 68$ & 0.000102 & 0.000005 & 0.14988 & 0.00061 & 0.11644 & 0.00014 & 0.11509 & 0.00020 & 1882 & 3 \\
\hline $\mathrm{RD} 12 \mathrm{~A} / 3$ & $32 / 66$ & 0.000096 & 0.000007 & 0.17248 & 0.00043 & 0.11679 & 0.00019 & 0.11542 & 0.00016 & 1887 & 2 \\
\hline $\mathrm{RD} 12 \mathrm{~A} / 4$ & $40 / 60$ & 0.000083 & 0.000004 & 0.15623 & 0.00038 & 0.11629 & 0.00031 & 0.11516 & 0.00032 & 1883 & 5 \\
\hline RD12A/6 & $32 / 40$ & 0.000152 & 0.000026 & 0.14637 & 0.00127 & 0.11759 & 0.00043 & 0.11602 & 0.00042 & 1896 & 7 \\
\hline RD12A/8 & $70 / 78$ & 0.000025 & 0.000015 & 0.16023 & 0.00045 & 0.11603 & 0.00015 & 0.11558 & 0.00028 & 1889 & 5 \\
\hline RD12A/9 & $38 / 54$ & 0.000145 & 0.000023 & 0.16228 & 0.00143 & 0.11685 & 0.00025 & 0.11499 & 0.00036 & 1880 & 6 \\
\hline Média & $282 / 432$ & & & & & & & Idade Média & s grāos = & 1886 & 3 \\
\hline \multicolumn{12}{|c|}{ Supergrupo Uatumã - Suite Intrusiva Mapuera - Granito Alto Pitinga (RD8A - Biotita-monzogranito) $1.888 \pm 3 \mathrm{Ma}$} \\
\hline RD8A/1 & $76 / 96$ & 0.000059 & 0.000008 & 0.16282 & 0.0051 & 0.11642 & 0.00021 & 0.11563 & 0.00023 & 1890 & 4 \\
\hline RD8A/2 & $52 / 52$ & 0.000120 & 0.000064 & 0.16344 & 0.01077 & 0.11771 & 0.00036 & 0.11586 & 0.00060 & 1894 & 10 \\
\hline $\mathrm{RD} 8 \mathrm{~A} / 3$ & $70 / 70$ & 0.000111 & 0.000089 & 0.17519 & 0.00546 & 0.11681 & 0.00118 & 0.11509 & 0.00018 & 1882 & 3 \\
\hline RD8A/4 & $28 / 44$ & 0.000081 & 0.000007 & 0.17126 & 0.00131 & 0.11668 & 0.00027 & 0.11552 & 0.00038 & 1888 & 6 \\
\hline RD8A/5 & $54 / 70$ & 0.000031 & 0.000007 & 0.16644 & 0.00162 & 0.11617 & 0.00026 & 0.11569 & 0.00022 & 1891 & 4 \\
\hline RD8A/6 & $32 / 36$ & 0.000076 & 0.000003 & 0.15738 & 0.00064 & 0.11656 & 0.00032 & 0.11561 & 0.00028 & 1890 & 4 \\
\hline Média & $312 / 368$ & & & & & & & Idade Média & s grãos = & 1888 & 3 \\
\hline
\end{tabular}

uma mesma unidade, séries magmáticas com características geoquímicas e idades diversas, o que levou vários pesquisadores (Dall' Agnol et al., 1987, 1994, 1999; Reis et al., 1999, 2000; Costi et al., 2000; Santos et al., 2000; Lamarão et al., 2002; Macambira et al., 2002) a sugerir a necessidade de uma melhor caracterização do Supergrupo Uatumã.

$\mathrm{O}$ mapeamento geológico realizado neste trabalho permitiu dividir o Grupo Iricoumé, na região da Província Pitinga, em três unidades estratigráficas distintas, formadas entre 1.89 e 1.88 $\mathrm{Ga}$. Estas unidades dispõem-se no interior e ao longo das bordas de uma estrutura em forma de arco (Ferron et al., 2002), de dimensão regional, cujo arranjo estrutural indica um ambiente distensivo para o vulcanismo na Província Pitinga. Este modelo tectônico, compreendendo estruturas anelares e diversas fácies vulcânicas e piroclásticas relacionadas a caldeiras, apresenta uma forte correlação ao modelo descrito por Juliani et al. (2005) e Lamarão et al. (2002) para as vulcânicas ácidas com $1.88 \mathrm{Ga}$ da província aurífera do Tapajós. A contemporaneidade entre as unidades vulcânicas da Província Pitinga e os granitos intrusivos da Suite Mapuera, como mostrado por suas idades, indicam claramente que estes granitos devem representar os equivalentes plutônicos das vulcânicas, o que poderá ser corroborado por suas características geoquímicas. Por ocorrerem associados à mega-estrutura anelar que hospeda as seqüências vulcânicas, presume-se que o posicionamento desses plutons foi influenciado ou controlado por processos de subsidência de caldeiras.

$\mathrm{Na}$ parte central dessa mega-estrutura (Figura 3) ocorrem os plutons da Suite Madeira. Como esses plutons são aproximadamente 50 milhões de anos mais jovens do que as rochas vulcânicas e os granitóides da Suite Mapuera da Província Pitinga, eles podem estar relacionados a um novo evento magmático. A colocação desses plutons, porém, deve ter ocorrido ou sido facilitada por reativação desse sistema distensivo antigo, que provavelmente ainda foi reativado aproximadamente 15 milhões de anos mais tarde, permitindo a ascensão dos magmas básicos que originaram sills e diques da Formação Quarenta Ilhas. 
No setor sudeste da Província Pitinga, nas proximidades do Rio Pitinga, rochas tufáceas ácidas da Formação Paraíso depositaram-se simultaneamente aos sedimentos da Formação Urupi. Neste setor observam-se intercalações entre depósitos vulcanoclásticos (sin-eruptivos), depósitos sedimentares vulcanogênicos, depósitos epiclásticos e depósitos sedimentares clásticos fluviais. Essas observações, e os dados geocronológicos apresentados, permitem sugerir que na Província Pitinga a colocação das unidades vulcânicas (Grupo Iricoumé) e deposição dos sedimentos vulcano-sedimentares (Formação Urupi) foram, ao menos em parte, contemporâneos. Intercalações de rochas tufáceas em sedimentos da Formação Urupi, ocorrendo desde a base até o topo da seqüência, foram primeiramente relatadas por Veiga Jr. et al. (1979). Todavia, esses autores relacionavam as rochas piroclásticas a eventos magmáticos mesoproterozói$\cos$ ( 1.5 a $1.6 \mathrm{Ga}$ - evento Parguaza), baseando-se em idades $\mathrm{Rb}$-Sr ou Ar-Ar determinadas para rochas básicas da Formação Quarenta Ilhas e as correlações com rochas piroclásticas similares que ocorrem intercaladas no Supergrupo Roraima. Recentemente, Santos et al. (2003) determinaram a idade de $1782 \pm 3$ Ma para rochas básicas intrusivas no Supergrupo Roraima. Essa idade é coincidente à da Formação Quarenta Ilhas (1780 $\pm 3 \mathrm{Ma}$ - Santos et al., 2002b), que é intrusiva na Formação Urupi, na Província Pitinga. Além disso, Santos et al. (2003) determinaram também a idade de $1873 \pm 3$ Ma para tufos ácidos intercalados nas porções superiores do Supergrupo Roraima, que é um intervalo de idade bastante próximo ao da Formação Paraíso, da Província Pitinga. Esses dados geocronológicos reforçam a provável correlação temporal entre a Formação Urupi, da Província Pitinga, e o Supergrupo Roraima.

CONCLUSÕES Rochas vulcânicas e graníticas Paleoproterozóicas da Província Pitinga, estudadas no presente trabalho, são relacionadas ao evento vulcânico-plutônico Uatumã. As rochas vulcânicas são correlacionadas ao Grupo Iricoumé e os granitos à Suíte Intrusiva Mapuera.

As rochas vulcânicas atribuidas ao Grupo Iricoumé foram, neste trabalho, divididas em três formações, para as quais são propostas as denominações de Formação Divisor, Formação
Paraíso e Formação Ouro Preto. A Formação Divisor compreende rochas vulcânicas intermediárias a ácidas. A Formação Paraíso é constituída por rochas piroclásticas ácidas, com idade ${ }^{207} \mathrm{~Pb} /{ }^{206} \mathrm{~Pb}$ em zircão de $1.890 \pm 2 \mathrm{Ma}$. A Formação Ouro Preto é constituída por rochas efusivas ácidas, com idade ${ }^{207} \mathrm{~Pb} /{ }^{206} \mathrm{~Pb}$ em zircão entre 1.881 e $1.886 \mathrm{Ma}$.

Foram determinadas também as idades ${ }^{207} \mathrm{~Pb} /{ }^{206} \mathrm{~Pb}$ em zircão dos plutons da Suíte Intrusiva Mapuera: Simão (1.882 $\pm 4 \mathrm{Ma}$, $1.885 \pm 4 \mathrm{Ma})$, Rastro (1.879 $\pm 5 \mathrm{Ma})$, Bom Futuro (1.882 \pm 3 Ma) e Alto Pitinga $(1.888 \pm 3 \mathrm{Ma}$ e $1.885 \pm 3 \mathrm{Ma})$.

Na região da Província Pitinga, a colocação das unidades vulcânicas e plutônicas é controlada por uma mega-estruturação regional de caráter distensivo, que provavelmente foi reativada várias vezes ao longo da evolução geológica da Província.

As relações geocronológicas associadas a observações de campo, petrográficas e litoquímicas, sugerem que o magmatismo na região da Província Pitinga experimentou pelo menos dois pulsos magmáticos principais, separados entre si por um intervalo de cerca de $50 \mathrm{Ma}$. O primeiro pulso teria ocorrido entre 1.890 e $1.881 \mathrm{Ma}$ e a ele estão relacionadas rochas vulcânicas efusivas e piroclásticas ácidas e intermediárias (Grupo Iricoumé), bem como os plutons Simão, Rastro, Bom Futuro e Alto Pitinga (Suíte Intrusiva Mapuera). O segundo pulso magmático teria ocorrido entre $1.829 \mathrm{Ma}$ e $1.798 \mathrm{Ma}$, envolvendo a geração dos granitos tipo-A da Suite Madeira.

As relações de campo verificadas no mapeamento realizado nesse trabalho, e as determinações geocronológicas realizadas, sugerem o caráter vulcano-sedimentar da Formação Urupi na região da Província Pitinga. A Formação Urupi apresenta intercalação entre rochas sedimentares vulcanogênicas e sedimentares clásticas e rochas piroclásticas da Formação Paraíso, do Grupo Iricoumé, o que indica a penecontemporaneidade dessas unidades.

Agradecimentos À ADIMB pelo suporte financeiro ao Projeto de Caracterização de Depósitos Minerais em Distritos Mineiros da Amazônia; à UFRGS e à UFPA (Pará-Iso) pelo apoio técnico-científico, e à MINERAÇÃO TABOCA S/A, pelo apoio logístico à realização deste trabalho.

\section{Referências}

Almeida M.E. \& Macambira M.J.B. 2003. Aspectos geológicos e litoquímicos dos granitóides cálcio-alcalinos paleoproterozóicos do sudeste de Roraima. In: SBGq, Congresso Brasileiro de Geoquímica, 9, Belém, Anais, p. 775-778.

Almeida M.E., Fraga L.M.B., Macambira M.J.B. 1997. New geochronological data of calc-alkaline granitoids of Roraima State, Brazil. In: South-American Symposium on Isotope Geology, Campos do Jordão-SP, Atas, p.34-37.

Almeida M.E., Macambira M.J.B., Faria M.S.G. 2002. A granitogênese paleoproterozóica do sul de Roraima. In: SBG, Congresso Brasileiro de Geologia, 41, João Pessoa, Anais, p. 434.

Almeida F.F.M., Hasui Y., Brito Neves B.B., Fuck R.A. 1981. Brazilian structural Provinces: an introduction. Earth-Sciences Reviews, 17:129.

Araújo Neto H. \& Moreira H.L. 1976. Projeto Estanho de Abonari. Relatório Final, DNPM/CPRM, Manaus, $2 \mathrm{v}$.

Borges R.M.K. 1997. Petrografia e química mineral dos greisens associados ao Granito Água Boa, mina Pitinga (AM): um estudo dos processos de formação de greisens. Dissertação de Mestrado, Centro de Geociências, Universidade Federal do Pará, 190 p.

Borges R.M.K. 2002. Greisens e epi-sienitos potássicos associados ao Granito Água Boa, Pitinga (AM): um estudo dos processos hidrotermais geradores de mineralizações estaniferas. Tese de Doutorado, Centro de Geociências, Universidade Federal do Pará, 348 p.
Carvalho Filho N.B., Horbe M.A., Souza P.C.B. 1984. A natureza dos depósitos de cassiterita do setor Madeira, região do Pitinga, Amazonas, Brasil, In: SBG/Núcleo Manaus, Symposium Amazônico, Manaus, Anais, 2, p. 459-461.

Costi H.T. 2000. Petrologia de granitos alcalinos com alto Flúor mineralizados em metais raros: o exemplo do albita-granito da mina Pitinga, Amazonas, Brasil. Tese de Doutorado, Centro de Geociências, Universidade Federal do Pará, 345 p.

Costi H.T., Dall'Agnol R., Moura C.A.V. 2000. Geology and Pb-Pb Geochronology of Paleoproterozoic Volcanic and Granitic Rocks of Pitinga Province, Amazonian Craton, Northern Brazil. International Geology Review, 42:832-849.

Dall'Agnol R., Lafon J.M., Macambira M.J.B. 1994. Proterozoic anorogenic magmatism in the Central Amazonian Province, Amazonian Craton: geochronological, petrological and geochemical aspects. Mineralogy and petrology, 50(1/3):113-138.

Dall'Agnol R., Costi H.T., Leite A.A.S., Magalhães M.S., Teixeira N.P., 1999. Rapakivi granites from Brazil and adjacent areas. Precambrian Research, 95:9-39.

Dall'Agnol R., Bettencourt J.S., Jorge João X.S.; Medeiros H., Costi H.T., Macambira, M.J.B., 1987. Granitogenesis in the northern Brasillian region - Areview. RBG - Revista Brasileira de Geociências, $17: 382-403$.

Daoud W.K. 1988. Granitos estaniferos de Pitinga, Amazonas: con- 
texto geológico e depósitos minerais associados. Dissertação de Mestrado, Instituto de Geociências, Universidade de Brasilia, Brasília, $194 \mathrm{p}$.

Daoud W.K. \& Antonietto Jr. A. 1985. Geologia do granite estanífero Água Boa, Pitinga, AM. In: SBG/NN, Simpósio de Geologia da Amazônia, 2, Belém, Anais, v.3, p. 17-33.

Daoud W.K. \& Fuck R.A. 1990. Contexto geológico e depósitos minerais associados aos granitos estaníferos de Pitinga, Amazonas. In: SBG, Congresso Brasileiro de Geologia, 36, Natal, Boletim de resumos, p. 114-115.

Faria M.S.G., Luzardo R., Pinheiro S.S., Silva L.C. 1999. Litoquímica e petrogênese do Granito Igarapé Azul - sudeste de Roraima. In: SBG/ Núcleo Norte, Simpósio de Geologia da Amazônia, 6, Manaus, Boletim de Resumos Expandidos, p. 577-580.

Faria M.S.G., Santos J.O.S., Luzardo R., Hartmann L.A., McNaughton N.J. 2002. The oldest island arc of Roraima State, Brazil - $2.03 \mathrm{Ga}$ : zircon SHRIMP U-Pb geochronology of Anauá Complex. In: SBG, Congresso Brasileiro de Geologia, 41, Boletim de Resumos, p. 306.

Faria M.S.G., Luzardo R., Pinheiro S.S., Reis N.J., Larizzatti, J.H., Riker S.L., Pessoa M. R. 2000. Projeto Folha Caracarai. Relatório Final. Programa de levantamentos geológicos básicos do Brasil. Folhas NA.20-Z-B e NA.20-Z-D (inteiras), NA.20-Z-A, NA.20-Z-C, NA.21Y-C e NA.21-Y-A (parciais), Estado de Roraima. Escala 1:500.000 Manaus-AM, CPRM.

Ferron J.M.T.M., Bastos Neto A.C., Rolim S.B.A., Hoff R., Umann L.V., Minuzzi O.R.R. 2002. Reconhecimento de uma mega-estrutura no Distrito Mineiro de Pitinga-AM: dados preliminares a partir da aplicação de técnicas de processamento digital de imagens ETM+ Landsat 7. In: SBG, Simpósio de Vulcanismo, 2, Belém-PA, Atas.

Fuck R.A., Pimentel M.M., Machado N., Daoud W.K. 1993. Idade U$\mathrm{Pb}$ do Granito Madeira, Pitinga (AM). In: Congresso Brasileiro de Geoquímica, 4, Anais, p. 246-248.

Horbe M.A., Horbe A.C., Costi H.T., Teixeira J.T. 1991. Geochemical characteristics of cryolite-tin-bearing granites from the Pitinga mine, northwestern Brazil: a review. Journal of Geochemical Exploration, 40:227-249.

Horbe M.A., Horbe A.C., Teixeira J.T., Costi H.T. 1985. Granito Madeira: petrologia, petroquímica e mineralizações. In: SBG-NN, Simpósio de Geologia da Amazônia, 2, Belém, Anais, v.3, p.284-320.

Issler R.S., Andrade A.R.F., Montalvão R.M.G., Guimarães G., Silva G.G., Lima M.I.C. 1974. Geologia da Folha SA.22, Belém. Rio de Janeiro, DNPM, Projeto RADAMBRASIL, Levantamento de Recursos Naturais, v. 5, p. 7-182.

Jorge João X.S., Santos, C.A., Provost A. 1985. Magmatismo adamelitico Água Branca (Folha Rio Mapuera, NW do Estado do Pará). In: SBG, Simpósio de Geologia da Amazônia, 2, Belém, Pará, Atas, v.2, p. 93-109.

Juliani C., Rye R.O., Nunes C.M.D., Silva R.H.C., Monteiro L.V.S., Neumann R., Alcover Neto A., Bettencourt J. S., Snee, L.W. 2005. Paleoproterozoic high-sulfidation mineralization in the Tapajós Gold Province, Amazonian craton, Brazil: geology, mineralogy, alunite argon age and stable isotopes constraints. Chemical Geology, 215:95125.

Lamarão C.N., Dall'Agnol R., Lafon J.M., Lima E.F. 2002. Geology, geochemistry, and $\mathrm{Pb}-\mathrm{Pb}$ zircon geochronology of the Paleoproterozoic magmatism of Vil Riozinho, Tapajós Gold Province, Amazonian craton, Brazil. Precambrian Research, 119(1):189-223.

Lenharo S.L. 1998. Evolução magmática e modelo metalogenético dos granitos mineralizados da região de Pitinga, Amazonas, Brasil. Tese de Doutoramento, Escola Politécnica, USP, São Paulo, 290p.

Lenharo S.L., Pollard P.J., Born H., Costi T.T. 1997. Topaz-bearing porphyritic phases within the Água Boa Granite, Pitinga tin mine, Amazonas, north Brazil. In: Second International Symposium on Grani- tes and Associated Mineralizations, Salvador, Extended Abstracts, SGM, p. 60-61.

Macambira M.J.B., Almeida M.E., Santos L.J. 2002. Idade de zircão de vulcânicas Iricoumé do sudeste de Roraima; contribuição para a redefinição do Supergrupo Uatumã. In: UFPA-CG/SBG-NO, Simpósio sobre Vulcanismo e Ambientes Associados, 2, Belém, Boletim de Resumos e Guia de Excursão, p. 22.

Macambira M.J.B., Teixeira J.T., Daoud W.K., Costi H.T. 1987. Geochemistry, mineralizations and age of tin-bearing granites from Pitinga, northwestern Brazil. Revista Brasileira de Geociências, 17:562570.

Mandetta P., Veiga JR. J.P., Oliveira J.R. 1974. Reconhecimento geológico ao longo do rio Pitinga, afluente do rio Uatumã. Manaus. CPRM, relatório interno, $31 \mathrm{p}$.

Melo A.F.F., Santos A.J., Cunha M.T.P., Campos M.J.F., D’Antona, R.J.G. 1978. Projeto Molibdênio em Roraima: relatório final. MME/ DNPM Manaus. 6v.

Oliveira M.J.R., Luzardo R., Faria M.S.G., Pinheiro S.S. 1996. A Suíte Intrusiva Água Branca no sudeste do Estado de Roraima. In: SBGNúcleo Norte, Simpósio de Geologia da Amazônia, 5, Belém-Pará, Atas, v. 2, p. 86-89.

Prado M., Ferron J.M.T.M., Lima E., Bastos Neto A., Pereira Vitor P., Minuzzi O. R. R., Pierosan, R. 2006. O Granito Europa e o Grupo Iricoumé na parte leste do Distrito Mineiro de Pitinga (Amazonas). Pesquisa em Geociências UFRGS (submetido).

Reis N.J., Faria M.S.G., Fraga L.M.B., Haddad R.C. 1999. Vulcanismo cálcio-alcalino paleoproterozóico do Setor Oriental do Estado de Roraima - Escudo das Guianas, In: Simpósio sobre Vulcanismo e Ambientes Associados, 1, Gramado. Boletim de Resumos, v.1.

Reis N.J., Faria M.S.G., Fraga L.M.B., Haddad R.C. 2000. Orosirian calc-alkaline volcanism and the Orocaima event in the northern Amazoniam Craton, eastern Roraima State, Brazil. Revista Brasileira de Geociências, 38(3):380-383.

Santos J.O.S. \& Reis Neto J.M. 1982. Algumas idades de rochas graníticas do Craton Amazônico. In: SBG, Congresso Brasileiro de Geologia, 32, Salvador, Atas, v.1., 339-348.

Santos J.O.S., Faria M.S.G., Hartmann L.A, McNaughton N.J. 2002a. Significant presence of the Tapajós-Parima belt in the Roraima region, Amazon craton based on SHRIMP U-Pb zircon geochronology. In: SBG, Congresso Brasileiro de Geologia, 41, Boletim de Resumos, p. 336

Santos J.O.S., Hartmann L.A., McNaugthon N.J., Fletcher I.R. 2002 b. Timmin of mafic magmatism in the Tapajós Province (Brazil) and implications for the evolution of the Amazon Craton: evidence from baddeleyite and zircon U-Pb SHRIMP geochronology. Journal of South America Earth Science, 15:409-429.

Santos J.O.S., Hartmann L.A., Gaudette H.E.; Groves D.I., Mc-Naugthon N.J., Fletcher L. R.A. 2000. New understanting of the Provinces of Amazon Craton based on Integration of Field Mapping and U-Pb and Sm-Nd geochronology. Gondwana Research, 3(4):453-488.

Santos J.O.S., Potter P.E., Reis N.J., Hartmann L.A., Fletcher I.R., McNaughton N.J. 2003. Age, source, and regional stratigraphy of the Roraima Supergroup and Roraima-like outliers in northern South America based on U-Pb geochronology. Geological Society of America Bulletin, 115(3):331-348.

Veiga JR. J.P., Nunes A.C.B., Fernandes A.S., Amaral J.E., Pessoa M. R., Cruz S.A.S. 1979. Projeto Sulfetos de Uatumã. Relatório Final, Manaus, DNPM/CPRM, 7v.

Manuscrito A1655 Aprovado em 01 de setembro de 2006 